\title{
The role of clay surfaces in the heterogeneous nucleation of calcite: Molecular dynamics simulations of cluster formation and attachment
}

\author{
Melinda A. Fodor ${ }^{\mathrm{a}}$, Zoltán Ható ${ }^{\mathrm{b}}$, Tamás Kristóf ${ }^{\mathrm{b}}$, Mihály Pósfai ${ }^{\mathrm{a}^{*}}$ \\ ${ }^{a}$ University of Pannonia, Department of Earth and Environmental Sciences, Veszprém, Hungary \\ ${ }^{b}$ University of Pannonia, Department of Physical Chemistry, Veszprém, Hungary \\ *mihaly.posfai@gmail.com
}

\begin{abstract}
In many environments calcium carbonate minerals precipitate in the presence of clay minerals, and observations suggest that clays, particularly smectites, facilitate carbonate formation. In order to understand the interactions between clay surfaces and carbonate-precipitating solutions, we built model aqueous solutions of various compositions (containing $\mathrm{Ca}^{2+}, \mathrm{Mg}^{2+}$ and $\mathrm{CO}_{3}{ }^{2-}$ ions) between layers of clay minerals (montmorillonite and kaolinite), and performed extensive molecular dynamics simulations. The results were compared with simulations for bulk solutions. Contrary to intuition, ionic clusters formed preferentially in the interlayer solution (instead of on the clay surface). The clusters grew both by the association of individual ions and aggregation, and were adsorbed to the clay surfaces with distinctly different efficiencies in the various systems. Montmorillonite was found to be more efficient than kaolinite in capturing clusters from solution. However, the efficiency of anchoring ionic clusters to the clay surfaces strongly depended on the $\mathrm{Na}^{+}$concentration of the solution, since $\mathrm{Na}^{+}$ appeared to strongly attach to the surface and thereby block it from clusters in the solution.

Montmorillonite (and probably other smectite clays as well) may thus have an important role in certain, primarily freshwater, systems in the localization of ionic clusters on its surface, thereby promoting the nucleation and templated growth of crystalline calcium-magnesium carbonate minerals.
\end{abstract}

Keywords: molecular dynamics, calcite, heterogeneous nucleation, montmorillonite, kaolinite, ionic clusters 


\section{Introduction}

The formation of crystalline solids from solution by heterogeneous nucleation is a common process both in nature and in artificial systems (Sosso et al., 2016). Long-standing views of how solids nucleate in solution, described by classical nucleation theory, have been challenged in the last two decades by both experimental and theoretical studies (De Yoreo et al., 2015; Gebauer and Cölfen, 2011;

Demichelis et al., 2011), driving much further research. Within the sprawling field of nucleation studies probably the calcium carbonate system has been most intensely studied, partly because of the widespread occurrence of calcium carbonate polymorphs in nature, their major roles in climate control and biomineralization, and their industrial uses (Sosso et al., 2016).

Results of both homogeneous calcium carbonate precipitation experiments and theoretical calculations strongly suggested that even before nucleation begins, stable 'prenucleation clusters' (PNCs) occur in solution (Gebauer and Cölfen, 2011; Gebauer et al., 2014; Demichelis et al., 2011). Although they can be composed of several tens of ions, these PNCs are thermodynamically stable, dynamic solutes with structural motifs that may relate to structural elements in specific crystalline polymorphs of calcium carbonate (Cartwright et al., 2012; Gebauer and Cölfen, 2011). Aggregation of PNCs then results in the formation of hydrated, amorphous calcium carbonate (ACC) (Gebauer et al., 2014), a precursor to crystalline polymorphs (Rodriguez-Blanco et al., 2010; Rodriguez-Navarro et al., 2015). However, the existence of PNCs and non-classical pathways in calcium carbonate nucleation were put in doubt by studies using both experimental and modelling approaches, the results of which were consistent with classical nucleation theory (Smeets et al., 2017; Henzler et al., 2018). These studies suggested the formation of 'dense liquid phases' (DLPs) by liquid-liquid separation. Thus, currently there is no consensus in the literature about the exact pathways leading to calcium carbonate nuclei.

Independent of whether the formation of clusters in supersaturated solutions follows classical or non-classical processes, these larger units can be important in various pathways of heterogeneous nucleation (Hu et al., 2012). New experimental techniques including cryo- and in situ TEM (Pouget et al., 2009; Smeets et al., 2015; Smeets et al., 2017) and synchrotron-based X-ray diffraction methods (De Yoreo et al., 2013) gave formerly unprecedented insight into the heterogeneous nucleation of carbonates on both mineral and organic surfaces, and in many cases provided evidence for amorphous liquid precursors attaching to pre-existing surfaces. Sheet silicates, particularly clay minerals, typically occur in the same natural environments where calcite precipitation occurs. Experimental studies suggest that the presence of mica can enhance carbonate nucleation rates (Li et al., 2014), and that 
calcite nucleation is templated by certain crystal surfaces of mica (Xu et al., 2018). In addition, clays from the smectite group have been found to enhance calcite precipitation (Kralj and Vdović, 2000) and to catalyze the formation of high-magnesian calcite or protodolomite (Liu et al., 2019). Thus, the interaction of clay surfaces with $\mathrm{CaCO}_{3}$ nuclei appears to affect carbonate mineral formation in many environments but, to our knowledge, atomic level details of this interplay have not been studied using large-scale molecular simulations.

The present study was motivated by our observation of ubiquitous associations of Mg-bearing calcite crystals with clay minerals of the smectite group in a freshwater environment (Lake Balaton, a large, calcareous lake in Hungary with a surface area of $590 \mathrm{~km}^{2}$ ). Based on morphological features (Figs. 1 and S1), we interpreted the calcite/smectite associations as evidence for the preferred heterogeneous nucleation of calcite on clay surfaces (Nyirö-Kósa et al., 2018), as opposed to calcite nucleating either homogeneously or on other surfaces such as cells and extrudates of microorganisms, a process that appears to be common in many aqueous environments (Dittrich and Obst, 2004; Dittrich and Sibler, 2005; Obst et al., 2009; Zhang et al., 2012; Zhang et al., 2015). Since Lake Balaton is rather shallow (on average $3.5 \mathrm{~m}$ deep), wind-driven turbulence typically stirs up its sediment particles and results in the presence of nm-scale clay flakes in the water. Another interesting feature of this lake is its relatively high dissolved $\mathrm{Mg}$ concentration (with a $\mathrm{Mg} / \mathrm{Ca}$ molar ratio typically ranging from 1 to 3), which results in the precipitation of calcite particles with highly variable Mg contents (Tompa et al., 2014). Thus, the understanding of molecular-scale mechanisms of calcite precipitation in Lake Balaton could be relevant to environments where calcite forms in the presence of clays, including not only shallow lakes but soils (Cuadros et al., 2016; Díaz-Hernández et al., 2013), subsurface aquifers (Makaremi et al., 2015) and even some technological settings such as drilling fluids and geological reservoirs used for $\mathrm{CO}_{2}$ trapping (Fernandez-Martinez et al., 2012). The assumed nucleation of Mgbearing carbonate on smectite clays could be also important for understanding the contemporary formation of dolomite (Díaz-Hernández et al., 2013; Liu et al., 2019; Pérez et al., 2015).

The goal of this study was to model interfaces of clays and solutions (with similar compositions as lakewater), and perform molecular dynamics (MD) simulations in order to understand the earliest stages of carbonate precipitation in heterogeneous systems. We wished to follow the formation of clusters and their distribution between individual clay layers. Two distinct clay layers were modeled and investigated, including kaolinite, a double layered clay in which the layers facing each other have opposite polarities, and montmorillonite, an expansive clay from the smectite group that has negatively charged surfaces. Nucleation processes in a bulk solution were compared with those in the heterogeneous clay/solution systems. Our calculations suggested a sequence of events starting with ion 
association in the liquid phase, followed by attachment of the formed clusters to the clay surfaces, with montmorillonite indeed being more efficient in capturing clusters than kaolinite.
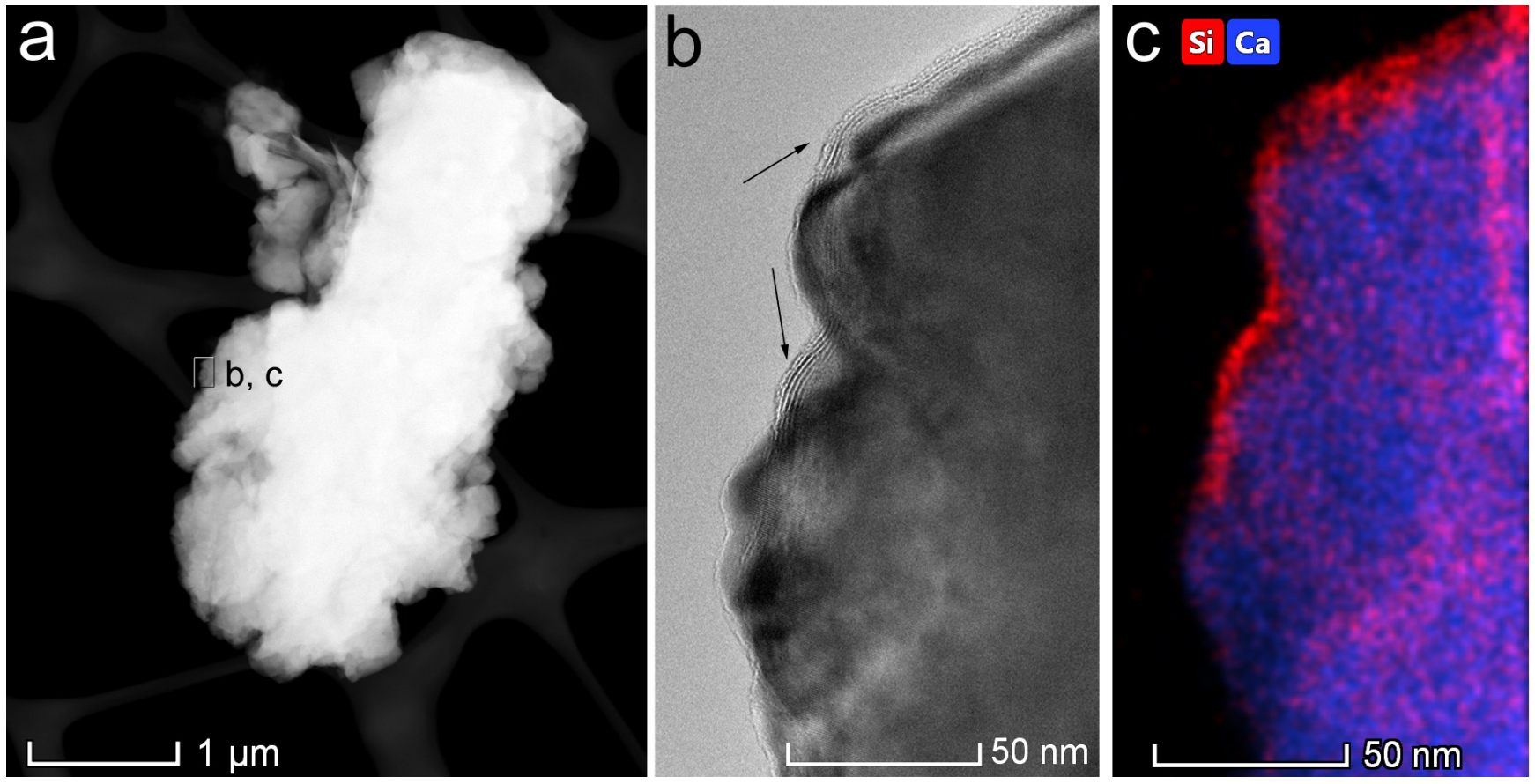

Figure 1. Transmission electron microscope images and elemental maps of associations of Mg-bearing calcite crystals with smectite clay flakes, collected from the water of Lake Balaton, suggesting that calcite nucleated heterogeneously on the clay mineral. (a) STEM HAADF image of a typical, singlecrystal Mg-bearing calcite particle; (b) and (c) HRTEM image and a STEM EDS elemental map of Si and $\mathrm{Ca}$, obtained form the small boxed area marked ' $\mathrm{b}, \mathrm{c}$ ' in (a), respectively, showing a 4-layer-thick smectite lamella (arrowed) attached to the calcite surface.

\section{Model construction and computational details}

We wished to build a model that represents conditions of calcite nucleation in Lake Balaton as faithfully as possible, including aqueous chemistry $\left(\mathrm{CO}_{3}{ }^{2-}, \mathrm{Ca}^{2+}\right.$ and $\mathrm{Mg}^{2+}$ ions in concentration ratios that are typically measured in the lakewater) and the presence of heterogeneous clay surfaces.

However, the complexity of the system and the limitations of available computing power required us to build models that deviate from the natural conditions (the ratio of the number of atoms in solution vs. in mineral layers being necessarily smaller than in the lake). In order to study the effects of certain parameters on calcite nucleation, we constructed several model systems, the compositions of which are shown in Table 1. The effects of two types of heterogeneous surfaces, kaolinite ('kaol') and montmorillonite ('mm') layers were compared. As a reference, we also performed MD simulations without any heterogeneous surface present ('bulk'). 
All models contained about 2 million atoms, most of which were included as atoms of water molecules. Among the other components, the number of $\mathrm{CO}_{3}{ }^{2-}$ ions was first set. Two types of systems with different concentrations were explored: a solution with $0.01 \mathrm{M} \mathrm{CO}_{3}{ }^{2-}$ (in the following: 'dilute system'), and another that contained $0.1 \mathrm{M} \mathrm{CO}_{3}{ }^{2-}$ (in the following: 'dense system', marked 'cc' in the system identifiers in Table 1). Even the dilute systems contained about twice as many $\mathrm{CO}_{3}{ }^{2-}$ ions than the natural lakewater (Tompa et al., 2014; Nyirö-Kósa et al., 2018). Nevertheless, if we assume that the negatively charged montmorillonite layers induce ion accumulation between the layers, our dilute model system may not have been far from being representative of natural conditions. At the same time, the modelling of dense systems was also useful for accelerating phenomena that were observed in the dilute systems as well.

The concentrations of the carbonate-forming cations $\mathrm{Mg}^{2+}$ and $\mathrm{Ca}^{2+}$ were set relative to that of $\mathrm{CO}_{3}{ }^{2-}$ (Table 1), with a 2.3:1 molar ratio of $\mathrm{Mg}: \mathrm{Ca}$, in accordance with experimental data obtained from Lake Balaton. Thus, $\mathrm{Mg}^{2+}$ is an essential component of the natural system. However, there are some concerns about the treatment of $\mathrm{Mg}^{2+}$ hydration by our model; in particular, the time scale of $\mathrm{Mg}^{2+}$ hydration/dehydration processes may be longer than our entire simulation time (Ikeda et al., 2007). Therefore, we also constructed model systems in which we studied the nucleation of carbonate in the absence of $\mathrm{Mg}^{2+}$ (marked 'noMg' in Table 1). In these simulations the number of $\mathrm{Ca}^{2+}$ ions was adjusted to compensate for the lack of $\mathrm{Mg}^{2+}$ (Table 1).

Concerning the cation compositions of our model solutions, an additional complexity is caused by the inclusion of montmorillonite layers. Whereas a kaolinite layer is electrostatically neutral, montmorillonite layers are negatively charged, this charge being compensated by interlayer cations in the mineral. Therefore, we added an appropriate amount of $\mathrm{Na}^{+}$ions to the model solution (systems with ' $\mathrm{Na}$ ' in their identifiers in Table 1), in order to ensure electroneutrality of the system, which resulted in way too many $\mathrm{Na}^{+}$ions compared to the ion composition of the lake. To approximate experimental compositions, two further model systems were built. First, the amount of $\mathrm{Na}^{+}$was decreased to half of the original concentration ('lessNa' in Table 1) and, in parallel, divalent cations were added to the model, using the original $\mathrm{Mg}^{2+}$ to $\mathrm{Ca}^{2+}$ ratio. Second, $\mathrm{Na}^{+}$ions were entirely removed from the montmorillonite model ('noNa'), and $\mathrm{Mg}^{2+}$ and $\mathrm{Ca}^{2+}$ ions were added using the same criteria as above (electroneutrality was kept). Necessarily, we had to deviate from the experimentally determined divalent cation to carbonate ratio in each case.

The composition of the kaolinite unit cell was $\mathrm{Al}_{2} \mathrm{Si}_{2} \mathrm{O}_{5}(\mathrm{OH})_{4}$ with $C 1$ space group symmetry and lattice parameters $a=0.52 \mathrm{~nm}, b=0.89 \mathrm{~nm}, c=0.74 \mathrm{~nm}, \alpha=91.93^{\circ}, \beta=105.05^{\circ}, \gamma=89.80^{\circ}$ (Bish, 1993). The applied kaolinite template was used to build a layer with a square ( $7 \times 7)$ arrangement of 
unit cells. Montmorillonite had a composition of $(\mathrm{K}, \mathrm{Na})_{0.321}\left[\mathrm{Si}_{4} \mathrm{O}_{8}\left[\mathrm{Al}_{1.679} \mathrm{Mg}_{0.321} \mathrm{O}_{2}(\mathrm{OH})_{2}\right]\right.$ and the lattice parameters were $a=0.36 \mathrm{~nm}, b=0.36 \mathrm{~nm}, c=1.20 \mathrm{~nm}$ (Heinz and Suter, 2004). The montmorillonite layers were created from $6 \times 7$ unit cells in the $x$ and $y$ spatial directions. The simulation boxes with kaolinite and montmorillonite were constructed using one kaolinite or montmorillonite layer with the solution above it, and then the whole system was duplicated in the $z$ direction. The final simulation boxes were rectangular parallelepipeds with dimensions of $22 \times 25 \times 38$ $\mathrm{nm}^{3}$.

\begin{tabular}{|c|c|c|c|c|c|c|c|c|c|}
\hline $\begin{array}{l}\text { System } \\
\text { type }\end{array}$ & System ID & System description & $\#$ of $\mathbf{H}_{2} \mathbf{O}$ & $\begin{array}{l}\# \text { of } \\
\mathbf{N a}^{+}\end{array}$ & $\begin{array}{c}\# \text { of } \\
\mathrm{Mg}^{2+}\end{array}$ & $\begin{array}{l}\# \text { of } \\
\mathrm{Ca}^{2+}\end{array}$ & $\begin{array}{c}\# \text { of } \\
\mathrm{CO}_{3}{ }^{2-}\end{array}$ & $\begin{array}{l}\text { Total \# } \\
\text { of ions }\end{array}$ & $\begin{array}{c}\text { Total } \\
\text { charge }\end{array}$ \\
\hline \multirow{8}{*}{ 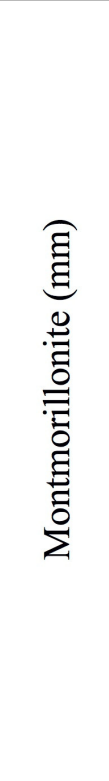 } & $\mathrm{mm}-\mathrm{Na}$ & \multirow{2}{*}{$\begin{array}{l}\mathrm{Na}^{+} \text {-rich solution } \\
\text { between } \\
\text { montmorillonite layers }\end{array}$} & 644962 & 1632 & 46 & 20 & 126 & 1824 & 1512 \\
\hline & mm-Na-cc & & 645206 & 2740 & 454 & 200 & 1268 & 4662 & 1512 \\
\hline & mm-lessNa & \multirow{2}{*}{$\begin{array}{l}\mathrm{Na}^{+} \text {-bearing solution } \\
\text { between } \\
\text { montmorillonite layers }\end{array}$} & 644046 & 816 & 330 & 144 & 126 & 1416 & 1512 \\
\hline & mm-lessNa-cc & & 642092 & 1372 & 928 & 410 & 1268 & 3978 & 1512 \\
\hline & $\mathrm{mm}-\mathrm{noNa}$ & \multirow{2}{*}{$\begin{array}{l}\mathrm{Na}^{+} \text {-free solution } \\
\text { between } \\
\text { montmorillonite layers }\end{array}$} & 644454 & 0 & 614 & 268 & 126 & 1008 & 1512 \\
\hline & mm-noNa-cc & & 642778 & 0 & 1406 & 618 & 1268 & 3292 & 1512 \\
\hline & mm-Na-noMg-cc & $\begin{array}{l}\mathrm{Na}^{+} \text {-rich, } \mathrm{Mg}^{2+} \text {-free } \\
\text { solution between } \\
\text { montmorillonite layers }\end{array}$ & 641408 & 2740 & 0 & 654 & 1268 & 4662 & 1512 \\
\hline & mm-noNa-noMg-cc & $\begin{array}{l}\mathrm{Na}^{+}-\text {and } \mathrm{Mg}^{2+} \text {-free } \\
\text { solution between } \\
\text { montmorillonite layers }\end{array}$ & 642778 & 0 & 0 & 2024 & 1268 & 3292 & 1512 \\
\hline \multirow{5}{*}{ 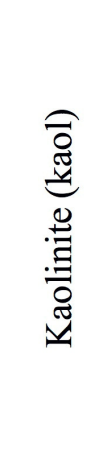 } & kaol-Na & \multirow{2}{*}{$\begin{array}{l}\mathrm{Na}^{+} \text {-bearing solution } \\
\text { between kaolinite } \\
\text { layers }\end{array}$} & 645236 & 120 & 46 & 20 & 126 & 312 & 0 \\
\hline & kaol-Na-cc & & 645204 & 1228 & 454 & 200 & 1268 & 3150 & 0 \\
\hline & kaol-noNa & \multirow{2}{*}{$\begin{array}{l}\mathrm{Na}^{+} \text {-free solution } \\
\text { between kaolinite } \\
\text { layers }\end{array}$} & 645296 & 0 & 92 & 34 & 126 & 252 & 0 \\
\hline & kaol-noNa-cc & & 645818 & 0 & 880 & 388 & 1268 & 2536 & 0 \\
\hline & kaol-noNa-noMg-cc & $\begin{array}{l}\mathrm{Na}^{+}-\text {and } \mathrm{Mg}^{2+} \text {-free } \\
\text { solution between } \\
\text { kaolinite layers }\end{array}$ & 645638 & 0 & 0 & 1268 & 1268 & 2536 & 0 \\
\hline \multirow{4}{*}{ 昙 } & bulk-Na & \multirow{2}{*}{$\begin{array}{l}\mathrm{Na}^{+} \text {-bearing solution } \\
\text { with no heterogeneous } \\
\text { surface present }\end{array}$} & 644524 & 120 & 46 & 20 & 126 & 312 & 0 \\
\hline & bulk-Na-cc & & 645568 & 1228 & 454 & 200 & 1268 & 3150 & 0 \\
\hline & bulk-noNa & \multirow{2}{*}{$\begin{array}{l}\mathrm{Na}^{+} \text {-free solution with } \\
\text { no heterogeneous } \\
\text { surface present }\end{array}$} & 646182 & 0 & 88 & 38 & 126 & 252 & 0 \\
\hline & bulk-noNa-cc & & 644584 & 0 & 880 & 388 & 1268 & 2536 & 0 \\
\hline
\end{tabular}

Table 1. Summary of the simulated systems, including notation, description and composition. (mm: montmorillonite; kaol: kaolinite; bulk: reference solution with no clay surface; cc: dense solution) 
MD simulations and the subsequent data analysis (density profiles, radial distribution function, cluster composition analysis) were carried out using the GROMACS software package (Berendsen et al., 1995; Hess et al., 2008). We applied the framework of a standard fully flexible all-atom force field, CHARMM (MacKerell Jr, 2001), and the thermodynamically consistent INTERFACE force field (Heinz et al., 2013). The parameters for kaolinite and montmorillonite were taken from the INTERFACE (v1.5) force field, and the other parameters including those of the interlayer $\mathrm{Na}^{+}$ions of montmorillonite were from the CHARMM database. Based on previous works (Ható et al., 2014; Kristóf et al., 2018) we found INTERFACE a suitable force field for modelling kaolinite. The CHARMM27 force field variant implemented in GROMACS (Bjelkmar et al., 2010) was used for inorganic ions. The parametrization of the Lennard-Jones part of this force field allowed the model, to a certain extent, to capture the characteristics of ion hydration. We used the fixed SPC model (Berendsen et al., 1981) for water molecules. Although the dominant dissolved carbon species in the lake is $\mathrm{HCO}_{3}{ }^{-}$ (at a $\mathrm{pH} \sim 8.5$ ), we simply used $\mathrm{CO}_{3}{ }^{2-}$ ions in our system as conventional atomistic force fields are not able to handle chemical reactions (deprotonation/protonation) between these ions.

In order to ensure appropriate system densities (practically, simulation box volumes $V$ ), preliminary $N p T$ (fixed number of molecules, $N$, constant pressure, $p$, and temperature, $T$ ) MD simulations were performed at $T=298 \mathrm{~K}$ and atmospheric pressure $(p=1.013 \mathrm{bar})$. The temperature and pressure controls were realized by velocity rescaling with a modified Berendsen thermostat (Bussi et al., 2007) and Berendsen barostat (Berendsen et al., 1984), respectively (the coupling time constants were $t_{\mathrm{T}}=0.1 \mathrm{ps}$ and $\mathrm{t}_{\mathrm{P}}=0.5 \mathrm{ps}$ ). The coupling of the pressure was semi-isotropic; isotropic in the $x$ and $y$ spatial directions but different in the $z$ direction of the simulation box which is perpendicular to the studied clay layers. The total $N p T$ simulation time needed to attain a constant system volume was between 300 and $2700 \mathrm{ps}$, depending on the model system. After the volume of the system had achieved a nearly constant value, it was fixed for the following $30 \mathrm{~ns} N V T$ (fixed number of molecules, constant volume and temperature) simulations, using the same temperature coupling. The leap-frog integrator was applied and the time step was set to $1 \mathrm{fs}$ in all cases. Periodic boundary conditions were used in all three spatial directions. The van der Waals interactions were truncated at $1.2 \mathrm{~nm}$ and the electrostatic interactions were calculated by the particle mesh Ewald (PME) algorithm (Darden et al., 1993) with $1.2 \mathrm{~nm}$ cutoff. All bonds involving hydrogen atoms were constrained with the linear constraint solver (LINCS) algorithm (Hess, 2008). 
Ion associations consisting of at least three ions were defined as clusters, and their sizes were analyzed using a standard GROMACS tool. Clusters were defined using a geometric criterion: an ion was considered part of a cluster if its distance from any aggregated ion was less than $0.42 \mathrm{~nm}$. This empirical parameter is close to the $\mathrm{Ca}-\mathrm{C}$ distance in carbonates (Smeets et al., 2017), and its validity was visually tested in several small test systems, using the powerful atom selection language and the visualization tools of the VMD software package (Humphrey et al., 1996). The ionic clusters were classified according to the distance between their center of mass and the center of the closest clay layer (along $z$ ). In this way two regions were defined: 1) a boundary region containing clusters within $1.5 \mathrm{~nm}$ from the clay layer, and 2) an interlayer region containing clusters beyond $1.5 \mathrm{~nm}$ from the clay layer. Cluster analysis results are presented below mostly as averages of selected 100-ps trajectory sections of the whole $N V T$ trajectories, except for the total numbers and size distributions of clusters, where analyses were performed at every $10,000^{\text {th }}$ MD step (equivalent to 10 -ps time intervals). Density profiles of the studied systems were recorded for the averages of the last $12 \mathrm{~ns}$ of the $30 \mathrm{~ns}$-long NVT simulations.

\section{Results}

Density profiles

The profiles for the dilute and dense systems showed highly similar features; thus, only the dilute cases are discussed here. As expected, in a bulk solution (i.e., in absence of any solid layer in the system) the ions did not display any preferential arrangement along the $z$ direction of the simulation box (Fig. S2), whereas the presence of clay layers caused significant changes in the distributions of ions and their clusters. In the presence of kaolinite layers the ions moved to the corresponding kaolinite surfaces with opposite polarities (Fig. 2a), resulting in the separation of oppositely charged ions. In the systems containing negatively charged montmorillonite layers, ions showed a symmetric distribution along $z$ (Figs. $2 \mathrm{~b}$ to $2 \mathrm{~d}$ ). $\mathrm{Na}^{+}$ions populated both sides of the clay layer, preventing the divalent cations from binding to the montmorillonite surface (Fig. 2b). An accumulation of $\mathrm{CO}_{3}{ }^{2-}$ ions, as well as the formation of ionic clusters were observed in the interlayer space. As the amount of $\mathrm{Na}^{+}$was decreased, the divalent cations could accumulate near the negatively charged surfaces (Figs. 2c and 2d). 
a
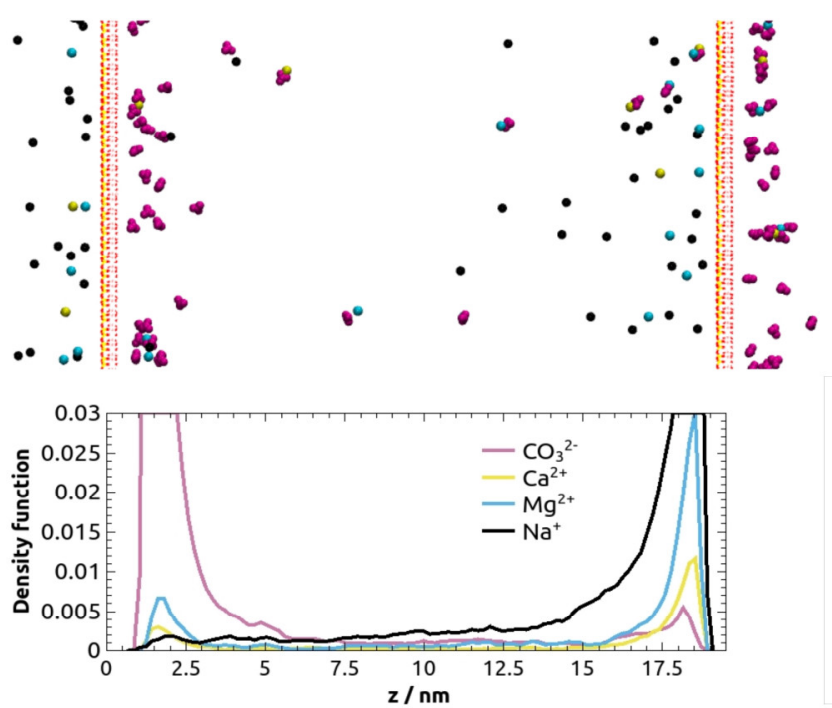

C
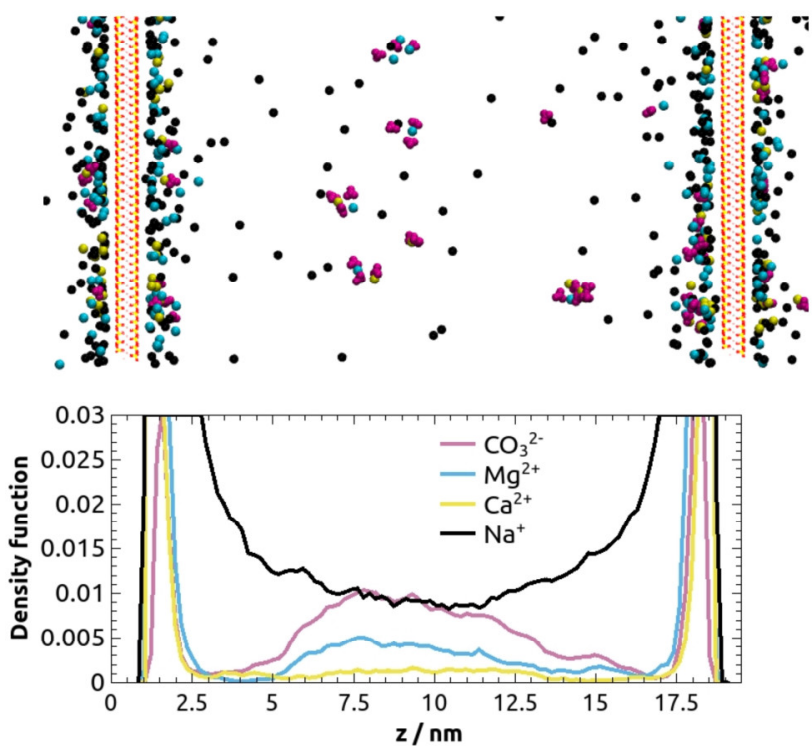

b
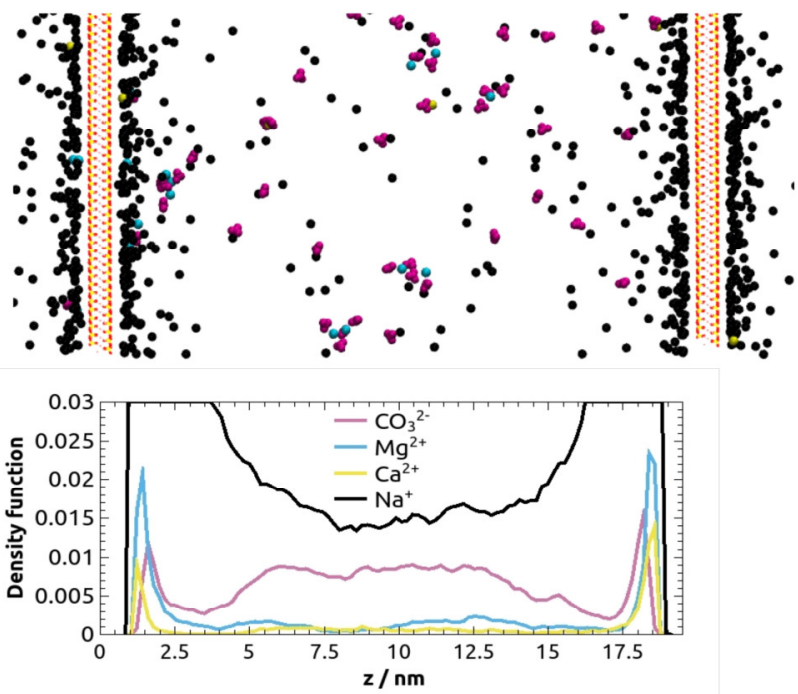

d
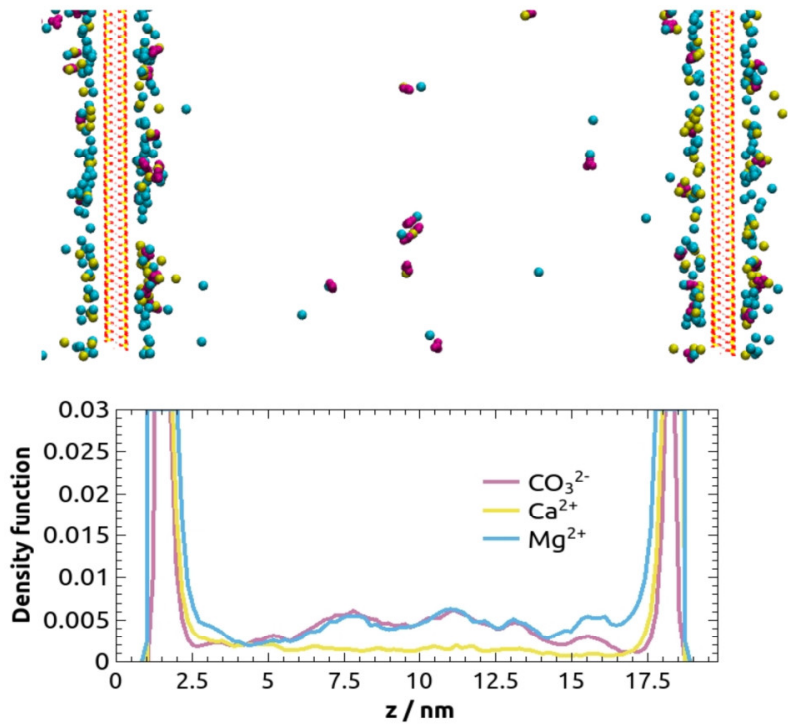

Figure 2. Density profiles and associated snapshots of dilute systems containing clay layers, after $30 \mathrm{~ns}$ simulations. (a) kaol-Na, (b) mm-Na, (c) mm-lessNa, and (d) mm-noNa (for the system notations see Table 1). (The simulation boxes were periodic but only slightly more than a quarter of the "unit cells" are shown here.)

\section{Number and size of clusters}

We compared the number of clusters (ion associations with 3 or more ions) that were present in the dilute systems at the end of the 30-ns $N V T$ simulation (Fig. 3a). At first glance, the systems with 
montmorillonite layers appeared to contain the largest number of clusters; however, as a result of the additional cations compensating for layer charge, these systems contained many more ions than the ones with kaolinite layers and the reference bulk solutions (Table 1). Thus, the three 'mm' systems can be meaningfully compared with one another only. Clearly, the reduction of the number of $\mathrm{Na}^{+}$ions enhanced cluster formation in these systems. The corresponding 'kaol' and 'bulk' systems contained the same number of ions and can be directly compared with one another. As in the ' $\mathrm{mm}$ ' systems, $\mathrm{Na}^{+}$ ions clearly reduced cluster formation in the 'kaol' system, whereas the number of clusters was about the same in the 'kaol-noNa' and 'bulk-noNa' systems.

Instead of using the absolute number of clusters as a measure of the effect of clay layers on cluster formation, it is more useful to examine the percentage of ions involved in cluster formation after $30 \mathrm{~ns}$ (Fig. 3b). Contrary to expectations, the presence of clay layers appeared to inhibit cluster formation. Whereas in the 'bulk-noNa'system $73 \%$ of all ions in the system were included in clusters by the end of the 30-ns calculation, in 'kaol-noNa' and 'mm-noNa' systems only 48 and $32 \%$ of ions were in clusters, respectively. This result is particularly surprising in the case of the 'mm' systems that involved more concentrated solutions than 'kaol' and 'bulk' systems, for reasons that were mentioned above. Again, in all three types of systems ('mm', 'kaol' and 'bulk') the reduction of $\mathrm{Na}^{+}$concentration appeared to enhance cluster formation. Since the number of $\mathrm{CO}_{3}{ }^{2-}$ ions was the same in all systems, we also analyzed the total $\mathrm{CO}_{3}{ }^{2-}$ content of the clusters (indirectly, by looking at the fraction of $\mathrm{CO}_{3}{ }^{2-}$ ions that remained in solution as free ions or in ion pairs). Interestingly, the clusters in the 'mmnoNa'system were most $\mathrm{CO}_{3}{ }^{2-}$-rich, to the point that $\mathrm{CO}_{3}{ }^{2-}$ ions were almost completely depleted from solution (Fig. 3b). Thus, while the presence of montmorillonite layers reduced the total number of clusters, it also resulted in the formation of $\mathrm{CO}_{3}{ }^{2-}$-richer clusters than in the other systems. In addition, the average charge of clusters was negative in all systems except in 'mm-lessNa' and 'mm-noNa', in which they were positive, even though the clusters in these systems contained the most $\mathrm{CO}_{3}{ }^{2-}$ ions as well. Concerning the evolution of size distributions of the clusters over the 30-ns simulations (Fig. S3), cluster sizes clearly increased with time, but small clusters (consisting of 3 and 4 ions) dominated in all systems. In all three types of systems ('mm', 'kaol' and 'bulk') a decrease in the number of $\mathrm{Na}^{+}$ions caused a slight shift of the distribution towards larger sizes. Interestingly, in the 'noNa' systems clusters with even numbers of ions (4,6 and 8) appeared to be more abundant than clusters containing odd numbers of ions (5 and 7) (Fig. S3); possible reasons for this behavior might be the tendency of divalent cations to form neutral clusters or to attain a configuration of higher symmetry.

Concerning cluster formation, the dense systems displayed similar features as the dilute ones; however, since in some dense cases by the end of the 30-ns simulation almost all ions were included in 
clusters, the differences between distinct systems are smaller (Fig. S4). Nevertheless, clusters formed most efficiently in the 'bulk' systems, whereas the clusters were most $\mathrm{CO}_{3}{ }^{2-}$-rich in the ' $\mathrm{mm}$ ' systems in the dense cases as well, suggesting that smectite layers have a positive effect on the initial stages of carbonate mineral formation. The omission of $\mathrm{Mg}^{2+}$ from the ' $\mathrm{mm}$ ' and 'kaol' systems (and their replacement by $\mathrm{Ca}^{2+}$ ) had little effect on cluster formation, other than making the clusters smaller.

a

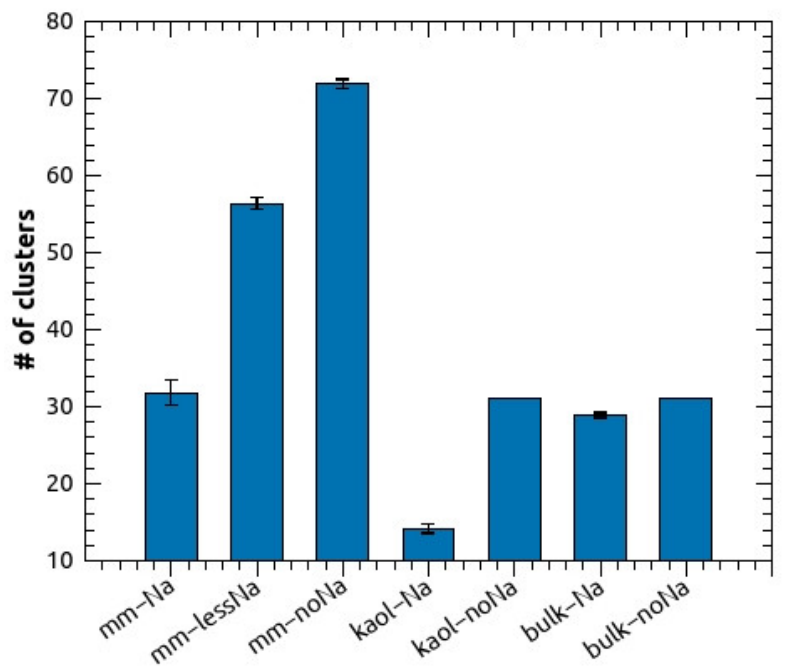

b

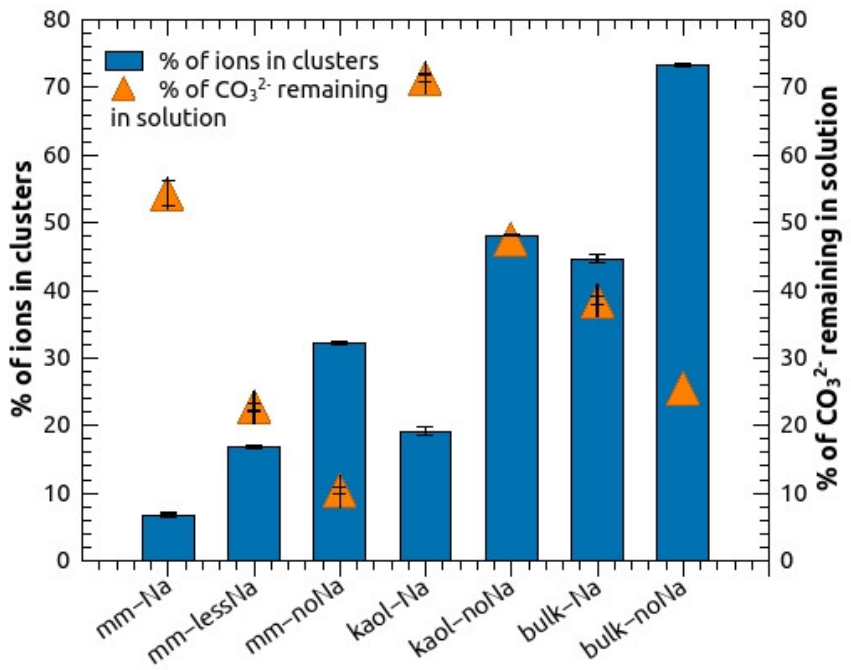

Figure 3. Cluster formation in the dilute systems after $30 \mathrm{~ns} N V T$ simulation, with clusters defined as ion associations of 3 or more ions. (a) Number of clusters that formed in selected systems; (b) fraction of all ions that were included in clusters (left axis) and the fraction of remaining $\mathrm{CO}_{3}{ }^{2-}$ ions that were not involved in cluster formation (right axis).

\section{Evolution of the number of clusters and their locations}

The changes in the number of clusters were analyzed at every $10,000^{\text {th }} \mathrm{MD}$ step (equivalent to 10 -ps time intervals) over the 30 ns-long NVT simulations (Fig. 4a). In addition, for two systems ('mmnoNa' and 'bulk-noNa') we performed 100-ns simulations, and analyzed the number of clusters at the endpoints of the simulations. The number of clusters increased with time in the dilute systems.

Whereas the $\mathrm{Na}^{+}$content did not affect the number of clusters in the two 'bulk' systems, it played a major role in the systems with clay layers: the less $\mathrm{Na}^{+}$was included in the starting composition, the more clusters formed. Again, apparently the 'mm-noNa' system contained the largest number of clusters over the entire simulation. The corresponding 'kaol' and 'bulk' systems contained the same total number of ions, and the change in the number of clusters was remarkably similar in the 'kaolnoNa' and the two 'bulk' systems. 
Concerning the endpoints of the two 100-ns runs, 'mm-noNa' and 'bulk-noNa' systems appear to behave differently: while the number of clusters slightly increases in the clay-bearing system from 30 to $100 \mathrm{~ns}$, the homogeneous system contains a smaller number of clusters at 100 than at $30 \mathrm{~ns}$. The reduction of cluster number in the bulk solution likely results from the combined effects of the depletion of free ions in the solution (even at 30 ns more than $70 \%$ of ions are already in clusters in 'bulk-noNa', see Fig. 3b) and the growth of clusters by aggregation. On the other hand, in the 'mmnoNa' system new clusters still form at $100 \mathrm{~ns}$, although the curve appears to reach a plateau. Another interesting feature of the curves in Fig. 4a is their "noisiness", a feature that we interpret as a manifestation of the dynamic nature of clusters. Visual inspection of a large number of quasi-videos constructed from 100-ps snapshots confirms that ions attach to and dissociate from clusters at a rate far exceeding the time resolution of our observation windows. Thus, the number of clusters fluctuates rapidly in any system, even though the trend of an increase in the number of clusters with time is clear. We note that their dynamic nature makes the identification of individual clusters impossible, precluding a detailed analysis of cluster geometry and ion coordination.

We studied the changes in the locations of clusters over time within the dilute systems that contained clay layers (Fig. 4b; Movie S1). The 'mm-Na' system was unique in that the number of clusters attached to the clay layer decreased with time, even though the total number of clusters in the system increased (see Fig. 4a). In all other heterogeneous systems the percentage of clusters near the clay layers increased at a rate significantly exceeding the rate of new cluster formation (compare the trends in Figs. $4 \mathrm{a}$ and $4 \mathrm{~b}$ ). The montmorillonite layer in the $\mathrm{Na}^{+}$-free system ('mm-noNa') appeared to be the most favorable surface for the attachment of clusters, since $75 \%$ of all clusters were adsorbed to it after $30 \mathrm{~ns}$. (Note that the number of clusters is small in the kaolinite systems, 14 and 31 in ' $k a o l-N a '$ and 'kaol-noNa', respectively, making the statistics of their distribution rather poor.) 

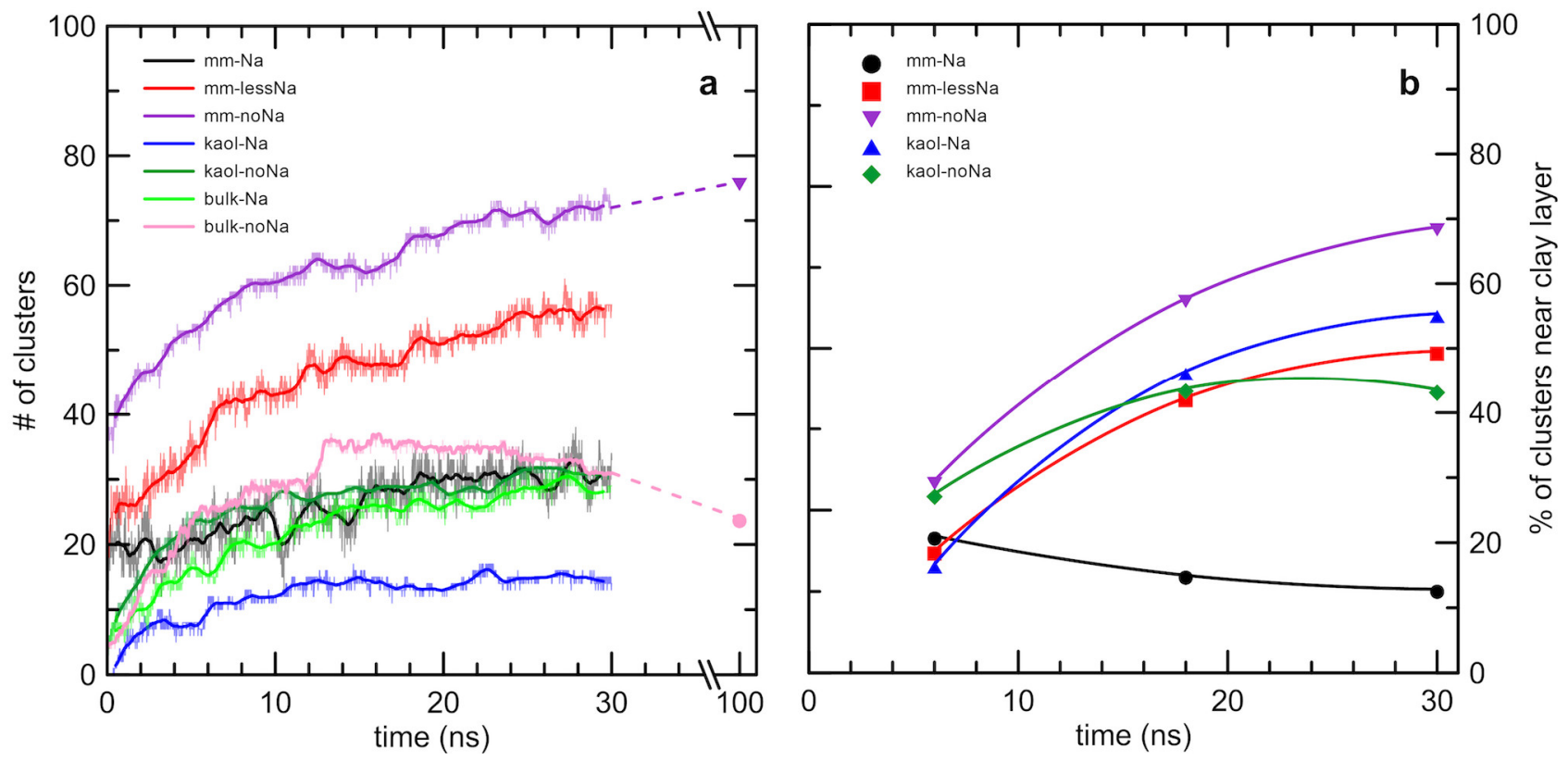

Figure 4. Changes in the number of clusters and their locations in the dilute systems. (a) Total number of clusters (ion associations of at least 3 ions; solid bold lines represent running averages; solid symbols indicate results of 100 ns-long NVT runs); (b) percentage of clusters that occur near the clay layers after 6, 18 and $30 \mathrm{~ns}$ (solid symbols), with curves fitted to the three points.
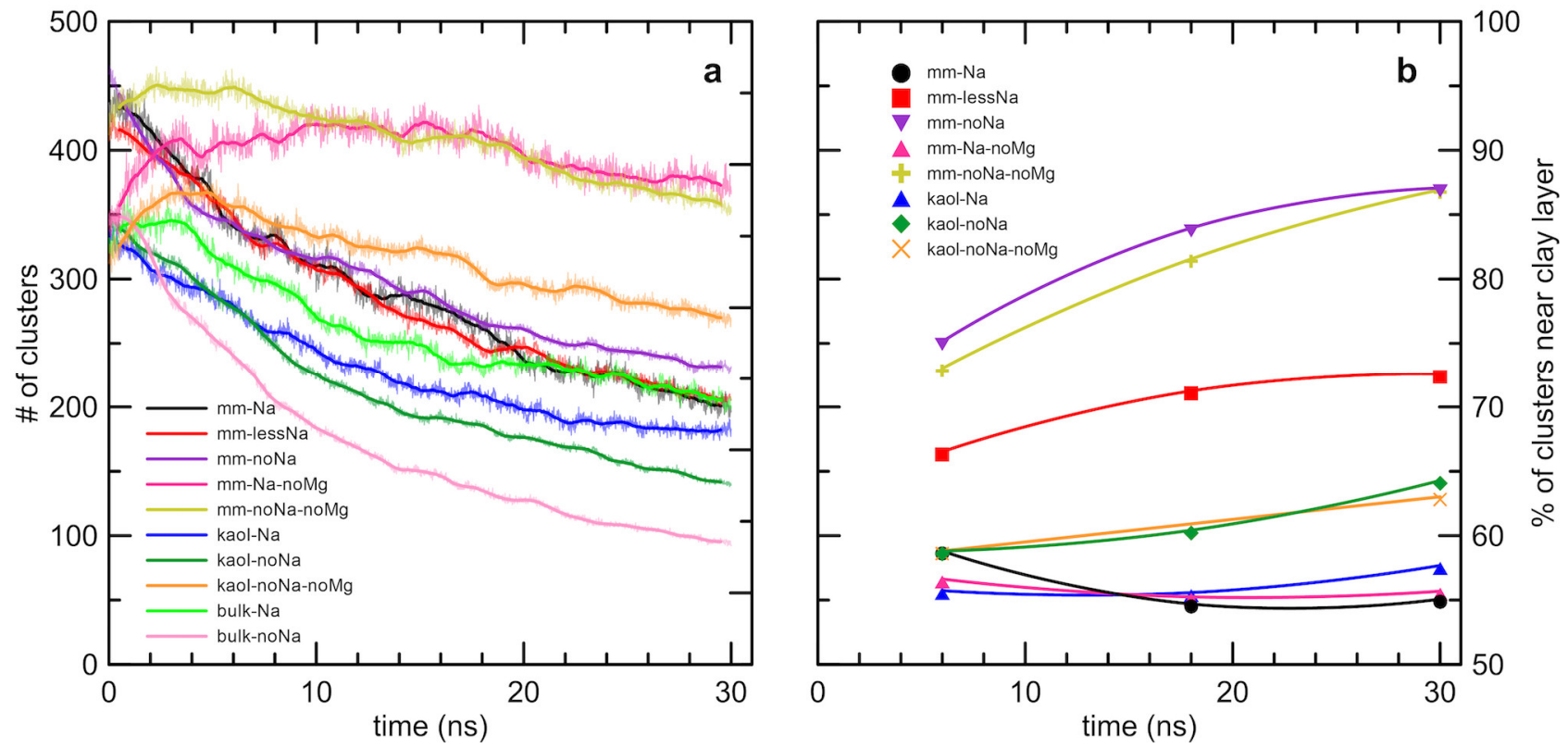

Figure 5. Change in the number of clusters and their locations in the dense systems. (a) Total number of clusters (ion associations of at least 3 ions, with solid bold lines representing running averages); (b) percentage of clusters that occur near the clay layers after 6, 18 and $30 \mathrm{~ns}$ (solid symbols), with curves fitted to the three points. 
In the dense systems the number of clusters diminished over time (Fig. 5a), as a result of the rapid aggregation of initial clusters in the concentrated solution and the depletion of free ions by the end of the simulation run. Apart from the Mg-free models, no significant differences could be identified among the distinct systems, suggesting that at such large oversaturations (as mentioned above, ion concentrations were about 20 times larger than in the lakewater) the presence and character of the heterogeneous surface matters little. The systems in which $\mathrm{Mg}^{2+}$ ions were replaced by $\mathrm{Ca}^{2+}$ (the three 'noMg' systems) contained significantly more clusters than all other systems, suggesting that only small clusters formed with $\mathrm{Ca}^{2+}$ as the only available divalent cation, and the initial clusters barely grew further during the simulation. Apparently, in $\mathrm{Mg}^{2+}$-bearing systems the initially small-sized clusters started to grow by aggregating to one other.

The number of clusters adsorbed to the clay layers showed very similar changes over time as in the dilute systems (Fig. 5b). Montmorillonite captured 74\% of all clusters from the solution in the $\mathrm{Na}^{+}-$ free systems, whereas kaolinite was much less efficient (29\%). As in the dilute systems, $\mathrm{Na}^{+}$ concentration played a major role in controlling whether the clusters remained in the interlayer space or attached to the clay layers. Concerning the locations of clusters, there was no difference between $\mathrm{Mg}$ bearing and $\mathrm{Mg}$-free systems, the percentages of clusters attached to the clay surfaces were practically the same in the corresponding systems.

Our models showed two fundamental effects in both dilute and dense systems, namely that $\mathrm{Mg}^{2+}$ and $\mathrm{Ca}^{2+}$ ions were much more likely to form clusters than $\mathrm{Na}^{+}$ions, and that the majority of the initial clusters formed in the solution, and not on the clay surface. When no $\mathrm{Na}^{+}$was present, divalent cations combined to produce positive ionic clusters in the presence of $\mathrm{CO}_{3}{ }^{2-}$ ions. Through the simulation run, in the absence of $\mathrm{Na}^{+}$, the number of clusters significantly decreased in the interlayer space between the layers. This reduction in the number of clusters in solution might be attributed partly to the growth of clusters by aggregation, but Figures $4 \mathrm{~b}$ and $5 \mathrm{~b}$ also suggest that the initially formed clusters moved to and adsorbed onto the clay layers. These two processes, the growth and adsorption of clusters are also illustrated by the snapshots taken from a dense montmorillonite system ('mm-noNacc'), shown in Figure 6 and Movie S2. Concerning the two types of clay surfaces, montmorillonite was clearly far more efficient than kaolinite in capturing clusters from the interlayer space (Figs. 4b and $5 b)$. 


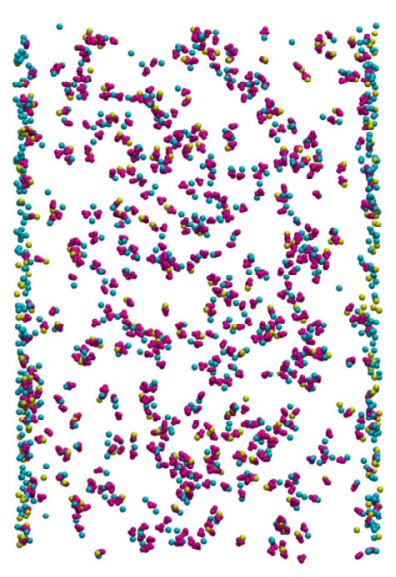

O ns

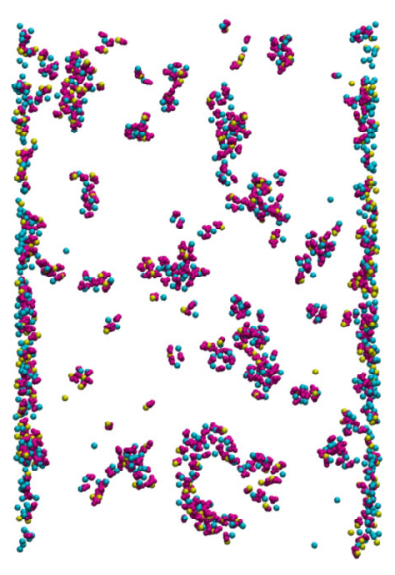

12 ns

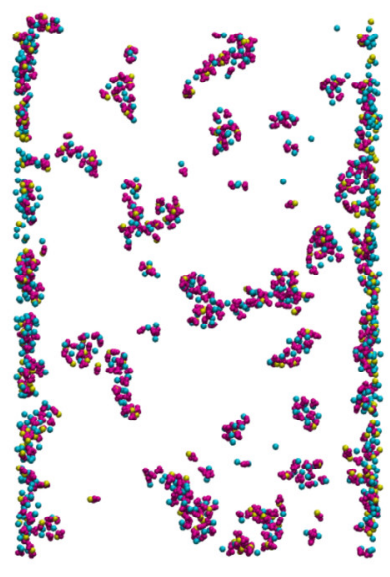

$18 \mathrm{~ns}$

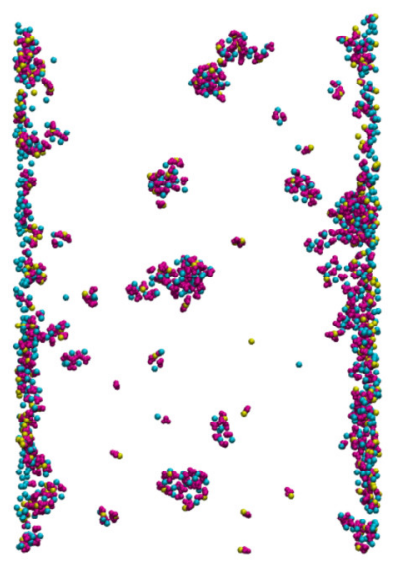

30 ns

Figure 6. Snapshots of cluster evolution between two layers of montmorillonite in a dense system ('mm-noNa-cc'); $\mathrm{CO}_{3}{ }^{2-}$ : magenta, $\mathrm{Mg}^{2+}$ : blue, $\mathrm{Ca}^{2+}$ : yellow. Initially small clusters form in the interlayer space, then they grow by aggregation and the majority of them moves to and adsorbs onto the clay layers.

\section{Composition of clusters}

We analyzed the compositions of the ion clusters that formed after 30-ns NVT runs in each system, with a focus on their $\mathrm{Mg}^{2+} / \mathrm{Ca}^{2+}$ ratio, compared with the initial $\mathrm{Mg}^{2+} / \mathrm{Ca}^{2+}=2.3$ value of the solution. The total charge of the clusters was predominantly negative in the dilute reference solution and in the 'kaol' systems, and the clusters contained more $\mathrm{Mg}^{2+}$ than $\mathrm{Ca}^{2+}$ ions, reflecting the original composition of the solution. Compared to the reference solution and kaolinite systems, in the presence of montmorillonite positively charged clusters were more abundant (the initial solution was positively charged, see Table 1), and dominated in the two systems with low $\mathrm{Na}^{+}$concentrations (' $\mathrm{mm}-\mathrm{lessNa}$ ' and 'mm-noNa'). We also studied the distribution of $\mathrm{Mg}^{2+} / \mathrm{Ca}^{2+}$ ratios of the clusters according to their locations with respect to the clay layers. In dilute heterogeneous systems the clusters near the clay surfaces had lower $\mathrm{Mg}^{2+} / \mathrm{Ca}^{2+}$ ratios compared to clusters in the interlayer region and to the clusters in the reference solution, whereas in the dense systems this effect was hardly noticeable (Figs. 7 and S5). 

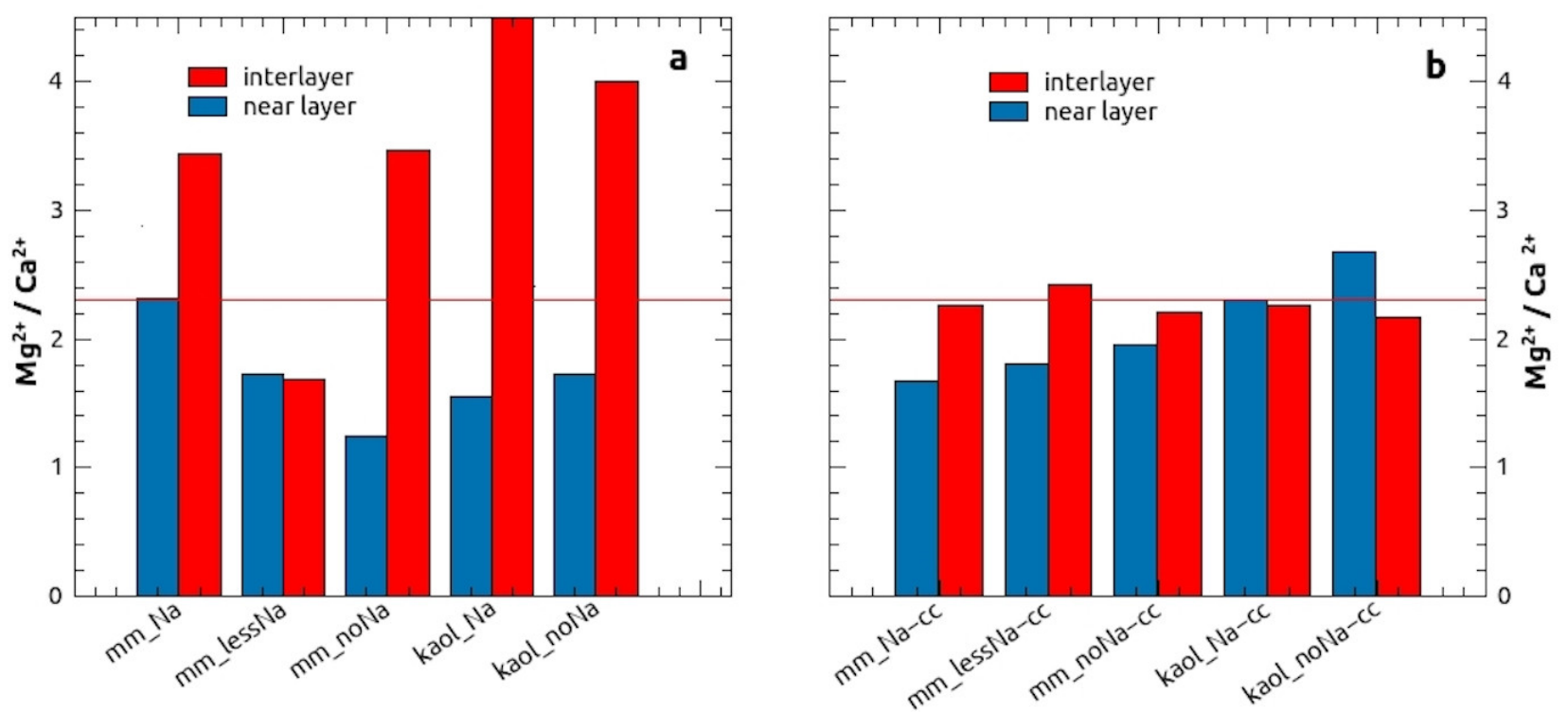

Figure 7. Comparison of $\mathrm{Mg}^{2+} / \mathrm{Ca}^{2+}$ ratios in clusters formed in heterogeneous (a) dilute and (b) dense systems after $30 \mathrm{~ns}$, as a function of the location of the clusters. The horizontal line indicates the original $\mathrm{Mg}^{2+} / \mathrm{Ca}^{2+}$ ratio of 2.3 in the solution.

The $\mathrm{Mg}^{2+} / \mathrm{Ca}^{2+}$ ratio changed with cluster size. We distinguished large clusters consisting of 10 or more ions vs. small clusters consisting of 3 to 9 ions. The small clusters had lower $\mathrm{Mg}^{2+} / \mathrm{Ca}^{2+}$ ratios than the large ones (Fig. 8). Over time we did not find any clear systematic variation in the $\mathrm{Mg} / \mathrm{Ca}$ ratio in either type of systems. Overall, it appears that larger and Mg-richer clusters remained in the solution, whereas smaller clusters with lower $\mathrm{Mg} / \mathrm{Ca}$ ratios were adsorbed onto the clay surfaces.

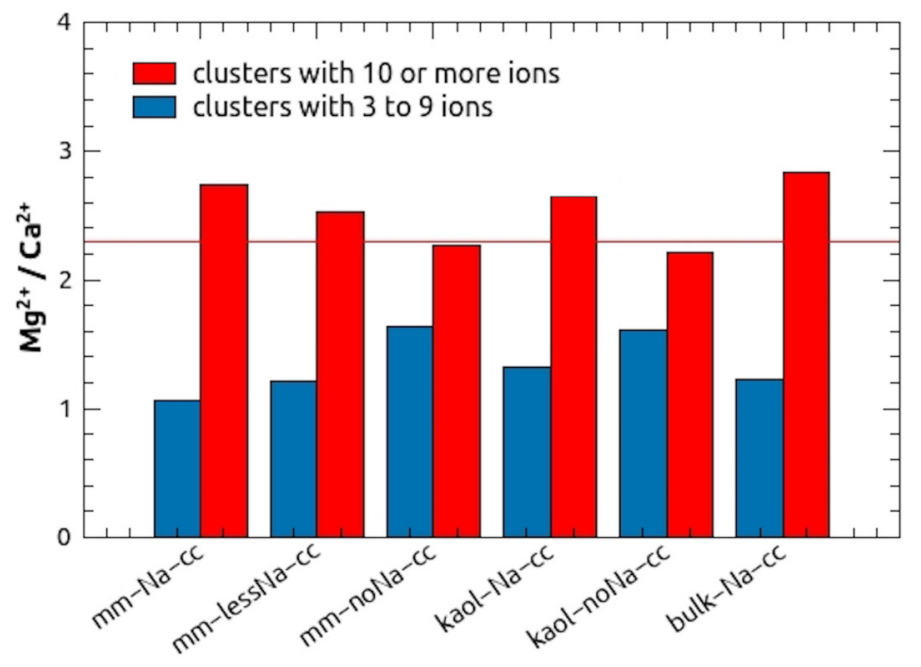

Figure $8 . \mathrm{Mg}^{2+} / \mathrm{Ca}^{2+}$ ratios of small (3 to 9 ions) and large (10 or more ions) clusters in dense systems. The horizontal line indicates the original $\mathrm{Mg}^{2+} / \mathrm{Ca}^{2+}$ ratio of 2.3 in the solution. 


\section{Discussion and conclusions}

With our MD simulations we set out to understand how Mg-bearing calcite crystals form in the presence of clays in a large lake. However, there are several orders of magnitude differences in length and time scales between the observations and simulations. Therefore, the model results in this study can provide information on processes that take place at the interface of clay layers and solutions before nucleation of carbonate crystals. Based on the sizes of the ionic clusters that formed within our 30-ns simulation times, they can be either PNCs (Gebauer et al., 2014; Gebauer et al., 2018) or pre-critical clusters (Smeets et al., 2017; Henzler et al., 2018). Regardless of whether the formation of the observed clusters follows classical or non-classical nucleation pathways, their attachment to heterogeneous surfaces may initiate carbonate nucleation. We observed distinct differences in cluster formation and attachment between the studied systems (bulk solution and solutions with kaolinite and montmorillonite layers), suggesting that the simulation results are indeed useful for understanding the initial stages of heterogeneous $\mathrm{Ca}-\mathrm{Mg}$ carbonate formation.

Concerning the heterogeneous model systems used in our calculations, questions may be raised whether such systems, i.e., individual clay layers $\sim 20 \mathrm{~nm}$ apart, can exist in water-based solutions. Cryo-TEM studies have shown that individual smectite layers can indeed occur in aqueous, low-ionicstrength solutions, with approximately parallel layers in both ordered and disordered conformations, in the latter case even several tens of nm apart (Gilbert et al., 2015; Tester et al., 2016). Kaolinite layers can be simply regarded as uncharged reference clay layers. Nevertheless, kaolinite can be also delaminated under certain conditions (Kristóf et al., 2018). Although the spacing of the clay layers was allowed to change in the simulations, it practically did not, due to the fixed amount of the interlayer aqueous phase. However, some vibrating motion of the clay layers was observable (Movies S1 and S2).

Our simulations strongly suggest that clusters form preferentially in the solution even when heterogeneous surfaces are present. Apparently, the clay layers rather inhibit than enhance initial cluster formation (Fig. 3b). In addition, the presence of a monovalent cation (in our systems, $\mathrm{Na}^{+}$) strongly inhibits cluster formation, especially in the systems with montmorillonite layers: the lower the concentration of $\mathrm{Na}^{+}$, the larger the number of clusters and the ratio of ions involved in cluster formation. It appears that the presence of $\mathrm{Mg}^{2+}$ also reduces the number of clusters but increases their sizes (probably by enhancing the aggregation rate of clusters through strong $\mathrm{Mg}^{2+}-\mathrm{CO}_{3}{ }^{2-}$ attraction), 
with the overall result that the ratio of ions involved in cluster formation is essentially the same in $\mathrm{Mg}$ free and Mg-bearing systems (Fig. S4).

Once clusters formed, they grow and, in the heterogeneous systems, get adsorbed onto clay layers. Montmorillonite is far more efficient than kaolinite in capturing clusters from solution (Figs. 4 and 5). This is probably due to the fact that in the 'mm' systems the interlayer solution has a positive charge, resulting in predominantly positively charged clusters in the interlayer space, which then move to the negatively charged montmorillonite surface. In contrast, in the case of kaolinite the interlayer solution is electrostatically neutral and the clusters are predominantly negatively charged. It appears that the clay surfaces preferentially adsorb the smaller clusters, which have a lower $\mathrm{Mg}^{2+} / \mathrm{Ca}^{2+}$ ratio than the starting solution; therefore, $\mathrm{a}^{2+} / \mathrm{Ca}^{2+}$ ratio close to 1 is typical for clusters attached to the clay.

Our results suggest that the main role of montmorillonite in the formation of carbonate nuclei is the collection of clusters that formed in the solution, by anchoring positively charged clusters to the negatively charged clay surface. We assume that these anchored clusters coalesce and grow further on the clay surface and eventually result in Mg-bearing calcite crystals. This formation mechanism may also affect the composition of crystal nuclei, with clay-adsorbed clusters approaching a $\mathrm{Mg}^{2+} / \mathrm{Ca}^{2+}$ ratio of $1 . \mathrm{Mg}^{2+}$ is known to have an inhibitory effect on calcite crystallization (Niedermayr et al., 2013), and the $\mathrm{Mg}^{2+} / \mathrm{Ca}^{2+}$ ratio employed in most of our model solutions (2.3) would favor the concurrent precipitation of metastable aragonite and calcite (Sun et al., 2015). However, in experimental studies the presence of a suitable substrate was found to alleviate the inhibitory effect of $\mathrm{Mg}^{2+}$ on calcite crystallization (Xu et al., 2018), consistent with our observations of clay-attached calcite particles (and the absence of aragonite) in Lake Balaton at relatively high (up to 4) $\mathrm{Mg}^{2+} / \mathrm{Ca}^{2+}$ ratios in lakewater (Nyirő-Kósa et al., 2018). Based on our simulations, the nature of this “substrate effect” is unclear; a visual inspection of the interfaces between montmorillonite and anchored clusters did not show any specific orientation relationships; thus, at the timescales of our model runs no templating effect was apparent. Moreover, the ions of the clusters do not bind directly to the atoms of the clay surface but rather through a layer of water. Both the clusters and the clay surfaces are hydrated, and even though the solvation shells of clusters are dynamic (Fig. S6), they are not shed when clusters become attached the clay (Fig. 9 and Movie S3). Nevertheless, the above model of cluster formation in solution and then sorption on montmorillonite surfaces, as derived from our simulations, appears to explain the initial stages of Mg-bearing calcite formation in the lake. 

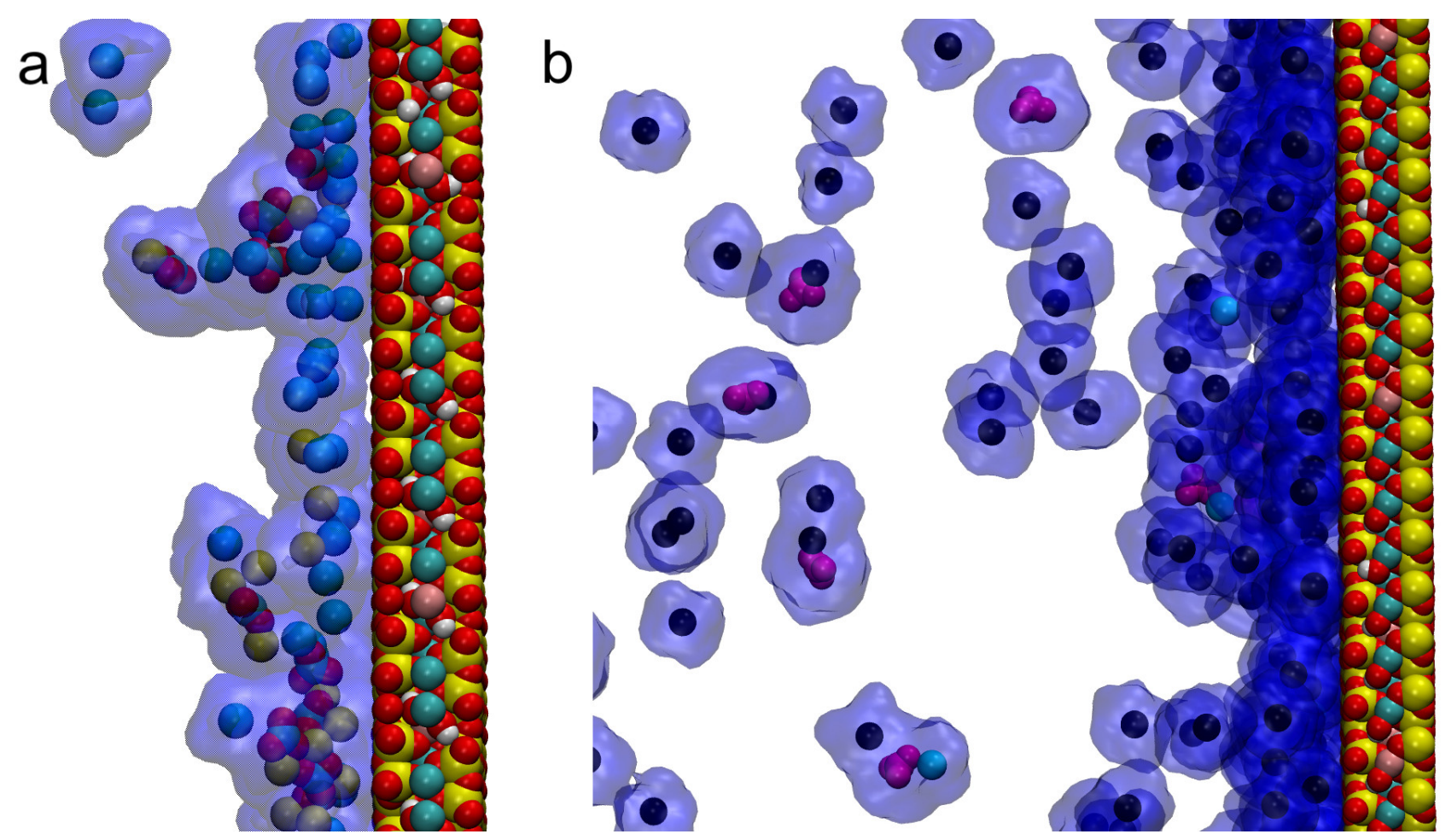

Figure 9. Snapshots from videos of simulation results, showing the attachment of ions and clusters to the montmorillonite surface through water molecules. (a) 'mm-noNa' system; (b) 'mm-Na' system. $\mathrm{CO}_{3}{ }^{2-}$ : magenta, $\mathrm{Mg}^{2+}$ : blue, $\mathrm{Ca}^{2+}$ : yellow, $\mathrm{Na}^{+}$: black. Water molecules are represented by the blue shaded area around the ions.

Finally, the role of $\mathrm{Na}^{+}$deserves special attention. It has a strong inhibitory effect on both cluster formation and on the anchoring of clusters to the clay layers (see Figures $4 \mathrm{~b}$ and $5 \mathrm{~b}$ ). The latter effect probably results from the larger affinity of $\mathrm{Na}^{+}$to be bound to the clay surface than those of divalent cations (Underwood et al., 2015; 2016), and thus $\mathrm{Na}^{+}$blocks the available surface sites from cluster attachment (see Fig. 9b). The $\mathrm{Na}^{+} /\left(\mathrm{Ca}^{2+}+\mathrm{Mg}^{2+}\right)$ atom ratio was highly variable among the various systems: it was extremely large (24.7) in ' $\mathrm{mm}-\mathrm{Na}$ ', whereas in all other systems ranged between 0 and 4.2 (see Table 1). Nevertheless, even in a system with a relatively small $\mathrm{Na}^{+} /\left(\mathrm{Ca}^{2+}+\mathrm{Mg}^{2+}\right)$ atom ratio (4.2 in 'mm-Na-cc') the clusters were prevented from attaching to the clay surface (Fig. 5b). Since the ratio of monovalent/divalent cations in typical ocean water is $\sim 7.6$, our results suggest that smectite will not function as a heterogeneous nucleation surface for calcite in seawater, and the smectiteenhanced calcite nucleation mechanism is effective in freshwater environments only. 


\section{Acknowledgements}

This research was supported by the National Office for Research, Development and Innovation (NKFIH, Hungary) under grants number K116732, K124353 and BIONANO-GINOP-2.3.2-15-201600017. Electron microscopy was performed at the Nanolab of the University of Pannonia, established using grant no. GINOP-2.3.3-15-2016-0009 from the European Structural and Investments Funds and the Hungarian Government. We gratefully acknowledge the computational support of the Paderborn Center for Parallel Computing for providing access to the OCuLUS cluster. We thank Dr. Valentina Erastova and two anonymous referees for their careful reviews and constructive comments that improved this study.

\section{References}

Berendsen, H. J. C., Postma, J. P. M., van Gunsteren, W. F., and Hermans, J.: Interaction models for water in relation to protein hydration, in: Intermolecular forces, edited by: Pullman, B., D. Reidel, Dordrecht, 331-342, 1981.

Berendsen, H. J. C., Postma, J. P. M. v., van Gunsteren, W. F., DiNola, A., and Haak, J. R.: Molecular dynamics with coupling to an external bath, J. Chem. Phys., 81, 3684-3690, 1984.

Berendsen, H. J. C., van der Spoel, D., and van Drunen, R.: GROMACS: a message-passing parallel molecular dynamics implementation, Comp. Phys. Comm., 91, 43-56, 1995.

Bish, D. L.: Rietveld refinement of the kaolinite structure at $1.5 \mathrm{~K}$, Clays Clay Min., 41, 738-744, 1993.

Bjelkmar, P., Larsson, P., Cuendet, M. A., Hess, B., and Lindahl, E.: Implementation of the CHARMM force field in GROMACS: Analysis of protein stability effects from correction maps, virtual interaction sites, and water models, J. Chem. Theory Comp., 6, 459-466, 2010.

Bussi, G., Donadio, D., and Parrinello, M.: Canonical sampling through velocity rescaling, J. Chem. Phys., 126, 014101, 2007.

Cartwright, J. H. E., Checa, A. G., Gale, J. D., Gebauer, D., and Sainz-Díaz, C. I.: Calcium carbonate polyamorphism and its role in biomineralization: how many amorphous calcium carbonates are there?, Angew. Chem. Int. Ed., 51, 11960-11970, 2012.

Cuadros, J., Diaz-Hernandez, J. L., Sanchez-Navas, A., Garcia-Casco, A., and Yepes, J.: Chemical and textural controls on the formation of sepiolite, palygorskite and dolomite in volcanic soils, Geoderma, 271, 99-114, 10.1016/j.geoderma.2016.01.042, 2016.

Darden, T., York, D., and Pedersen, L.: Particle mesh Ewald: An N·log (N) method for Ewald sums in large systems, 98, 10089-10092, 1993.

De Yoreo, J. J., Waychunas, G. A., Jun, Y. S., and Fernandez-Martinez, A.: In situ investigations of carbonate nucleation on mineral and organic surfaces, Rev. Min. Geochem., 77, 229-257, 2013.

De Yoreo, J. J., Gilbert, P. U. P. A., Sommerdijk, N. A. J. M., Penn, R. L., Whitelam, S., Joester, D., Zhang, H., Rimer, J. D., Navrotsky, A., and Banfield, J. F.: Crystallization by particle attachment in synthetic, biogenic, and geologic environments, Science, 349, aaa6760, 10.1126/science.aaa6760, 2015. 
Demichelis, R., Raiteri, P., Gale, J. D., Quigley, D., and Gebauer, D.: Stable prenucleation mineral clusters are liquid-like ionic polymers, Nature Comm., 2, 590, 2011.

Díaz-Hernández, J. L., Sánchez-Navas, A., and Reyes, E.: Isotopic evidence for dolomite formation in soils, Chem. Geol., 347, 20-33, 10.1016/j.chemgeo.2013.03.018, 2013.

Dittrich, M., and Obst, M.: Are picoplankton responsible for calcite precipitation in lakes?, 33, 559564, 10.1579/0044-7447-33.8.559, 2004.

Dittrich, M., and Sibler, S.: Calcium carbonate precipitation by cyanobacterial polysaccharides, Geol. Soc. Spec. Pub., 336, 51-63, 10.1144/SP336.4, 2005.

Fernandez-Martinez, A., Hu, Y., Lee, B., Jun, Y. S., and Waychunas, G. A.: In situ determination of interfacial energies between heterogeneously nucleated $\mathrm{CaCO} 3$ and quartz substrates: thermodynamics of CO2 mineral trapping, Env. Sci. Tech., 47, 102-109, 2012.

Gebauer, D., and Cölfen, H.: Prenucleation clusters and non-classical nucleation, Nano Today, 6, 564584, 10.1016/j.nantod.2011.10.005, 2011.

Gebauer, D., Kellermeier, M., Gale, J. D., Bergström, L., and Cölfen, H.: Pre-nucleation clusters as solute precursors in crystallisation, Chem. Soc. Rev., 43, 2348-2371, 2014.

Gebauer, D., Raiteri, P., Gale, J. D., and Cölfen, H.: On classical and non-classical views on nucleation, Amer. J. Sci., 318, 969-988, 2018.

Gilbert, B., Comolli, L. R., Tinnacher, R. M., Kunz, M., and Banfield, J. F.: Formation and restacking of disordered smectite osmotic hydrates, Clays Clay Mineral., 63, 432-442, 10.1346/CCMN.2015.0630602, 2015.

Ható, Z., Makó, É., and Kristóf, T.: Water-mediated potassium acetate intercalation in kaolinite as revealed by molecular simulation, J. Mol. Modeling, 20, 2140, 2014.

Heinz, H., and Suter, U. W.: Surface structure of organoclays, Angew. Chem. Int. Ed., 43, 2239-2243, 2004.

Heinz, H., Lin, T.-J., Kishore Mishra, R., and Emami, F. S.: Thermodynamically consistent force fields for the assembly of inorganic, organic, and biological nanostructures: the INTERFACE force field, Langmuir, 29, 1754-1765, 2013.

Henzler, K., Fetisov, E. O., Galib, M., Baer, M. D., Legg, B. A., Borca, C., Xto, J. M., Pin, S., Fulton, J. L., Schenter, G. K. and Govind, N.: Supersaturated calcium carbonate solutions are classical, Science Adv., 4, p.eaao6283, 2018.

Hess, B.: P-LINCS: A parallel linear constraint solver for molecular simulation, J. Chem. Theory Comp., 4, 116-122, 2008.

Hess, B., Kutzner, C., Van Der Spoel, D., and Lindahl, E.: GROMACS 4: algorithms for highly efficient, load-balanced, and scalable molecular simulation, J. Chem. Theory Comp., 4, 435-447, 2008.

Hu, Q., Nielsen, M. H., Freeman, C. L., Hamm, L. M., Tao, J., Lee, J. R. I., Han, T. Y.-J., Becker, U., Harding, J. H., and Dove, P. M.: The thermodynamics of calcite nucleation at organic interfaces: Classical vs. non-classical pathways, Faraday Discuss., 159, 509-523, 2012.

Humphrey, W., Dalke, A., and Schulten, K., VMD: visual molecular dynamics, J. Mol. Graphics, 14, 33-38, 1996.

Ikeda, T., Boero, M., and Terakura, K.: Hydration properties of magnesium and calcium ions from constrained first principles molecular dynamics, J. Chem. Phys., 127, 074503, 2007.

Kralj, D., and Vdović, N.: The influence of some naturally occurring minerals on the precipitation of calcium carbonate polymorphs, Water Res., 34, 179-184, 10.1016/S0043-1354(99)00110-4, 2000.

Kristóf, T., Sarkadi, Z., Ható, Z., and Rutkai, G.: Simulation study of intercalation complexes of kaolinite with simple amides as primary intercalation reagents, Comp. Mater. Sci., 143, 118$125,2018$. 
Li, Q., Fernandez-Martinez, A., Lee, B., Waychunas, G. A., and Jun, Y.-S.: Interfacial energies for heterogeneous nucleation of calcium carbonate on mica and quartz, Envir. Sci. Technol., 48, 5745-5753, 2014.

Liu, D., Xu, Y., Papineau, D., Yu, N., Fan, Q., Qiu, X., and Wang, H.: Experimental evidence for abiotic formation of low-temperature proto-dolomite facilitated by clay minerals, Geochim. Cosmochim. Acta, 247, 83-95, 2019.

MacKerell Jr, A. D.: Atomistic models and force fields, in: Computational Biochemistry and Biophysics, edited by: Becker, O. M., MacKerell Jr, A. D., Roux, B., and Watanabe, M., Marcel Dekker, Inc., New York, 19-50, 2001.

Makaremi, M., Jordan, K. D., Guthrie, G. D., and Myshakin, E. M.: Multiphase Monte Carlo and molecular dynamics simulations of water and $\mathrm{CO} 2$ intercalation in montmorillonite and beidellite, J. Phys. Chem. C, 119, 15112-15124, 2015.

Niedermayr, A., Köhler, S. J., and Dietzel, M.: Impacts of aqueous carbonate accumulation rate, magnesium and polyaspartic acid on calcium carbonate formation (6-40 C), Chem. Geol., 340, 105-120, 10.1016/j.chemgeo.2012.12.014, 2013.

Nyirő-Kósa, I., Rostási, Á., Bereczk-Tompa, É., Cora, I., Koblar, M., Kovács, A., and Pósfai, M.: Nucleation and growth of Mg-bearing calcite in a shallow, calcareous lake, Earth Planet. Sci. Lett., 496, 20-28, 2018.

Obst, M., Wehrli, B., and Dittrich, M.: $\mathrm{CaCO}_{3}$ nucleation by cyanobacteria: laboratory evidence for a passive, surface-induced mechanism, Geobiol., 7, 324-347, 10.1111/j.1472-4669.2009.00200.x, 2009.

Pérez, A. M., Zarza, A. M. A., La Iglesia, Á., and García, R. M.: Do magnesian clays play a role in dolomite formation in alkaline environments? An example from Castanar Cave, Cáceres (Spain), Geogaceta, 57, 15-18, 2015.

Pouget, E. M., Bomans, P. H. H., Goos, J. A. C. M., Frederik, P. M., and Sommerdijk, N. A. J. M.: The initial stages of template-controlled $\mathrm{CaCO}_{3}$ formation revealed by cryo-TEM, Science, 323, 1455-1458, 10.1126/science.1169434, 2009.

Rodriguez-Blanco, J. D., Shaw, S., and Benning, L. G.: The kinetics and mechanisms of amorphous calcium carbonate (ACC) crystallization to calcite, via vaterite, Nanoscale, 3, 265-271, 2010.

Rodriguez-Navarro, C., Kudlacz, K., Cizer, Ö., and Ruiz-Agudo, E.: Formation of amorphous calcium carbonate and its transformation into mesostructured calcite, CrystEngComm, 17, 58-72, 2015.

Smeets, P. J. M., Cho, K. R., Kempen, R. G. E., Sommerdijk, N. A. J. M., and De Yoreo, J. J.: Calcium carbonate nucleation driven by ion binding in a biomimetic matrix revealed by in situ electron microscopy, Nature Mater., 14, 394-399, 10.1038/nmat4193, 2015.

Smeets, P. J. M., Finney, A. R., Habraken, W. J. E. M., Nudelman, F., Friedrich, H., Laven, J., De Yoreo, J. J., Rodger, P. M., and Sommerdijk, N. A. J. M.: A classical view on nonclassical nucleation, Proc. Natl. Acad. Sci. USA, 114, E7882-E7890, 2017.

Sosso, G. C., Chen, J., Cox, S. J., Fitzner, M., Pedevilla, P., Zen, A., and Michaelides, A.: Crystal nucleation in liquids: Open questions and future challenges in molecular dynamics simulations, Chem. Rev., 116, 7078-7116, 10.1021/acs.chemrev.5b00744, 2016.

Sun, W., Jayaraman, S., Chen, W., Persson, K. A., and Ceder, G.: Nucleation of metastable aragonite $\mathrm{CaCO}_{3}$ in seawater, Proc. Natl. Acad. Sci. USA, 112, 3199-3204, 2015.

Tester, C. C., Aloni, S., Gilbert, B., and Banfield, J. F.: Short-and long-range attractive forces that influence the structure of montmorillonite osmotic hydrates, Langmuir, 32, 12039-12046, 10.1021/acs.langmuir.6b03265, 2016.

Tompa, É., Nyirő-Kósa, I., Rostási, Á., Cserny, T., and Pósfai, M.: Distribution and composition of Mg-calcite and dolomite in the water and sediments of Lake Balaton, Central Eur. Geol., 57, 113136, 10.1556/CEuGeol.57.2014.2.1, 2014. 
Underwood, T., Erastova, V., Cubillas, P., Greenwell, H. C.: Molecular dynamic simulations of montmorillonite-organic interactions under varying salinity: an insight into enhanced oil recovery, J. Phys. Chem. C, 119, 7282-7294, 2015.

Underwood, T., Erastova, V. and Greenwell, H. C.: Ion adsorption at clay-mineral surfaces: the Hofmeister series for hydrated smectite minerals, Clays Clay Minerals, 64, 472-487, 2016.

Xu, H., Zhou, M., Fang, Y., and Teng, H. H.: Effect of mica and hematite (001) surfaces on the precipitation of calcite, Minerals, 8, 17, 2018.

Zhang, F., Xu, H., Konishi, H., Shelobolina, E. S., and Roden, E.: Polysaccharide-catalyzed nucleation and growth of disordered dolomite: A potential precursor of sedimentary dolomite, Amer. Mineral., 97, 556-567, 2012.

Zhang, F., Xu, H., Shelobolina, E. S., Konishi, H., Converse, B., Shen, Z., and Roden, E. E.: The catalytic effect of bound extracellular polymeric substances excreted by anaerobic microorganisms on $\mathrm{Ca}-\mathrm{Mg}$ carbonate precipitation: Implications for the "dolomite problem", Amer. Mineral., 100, 483-494, 10.2138/am-2015-4999, 2015. 


\section{Supplementary Information}

The role of clay surfaces in the heterogeneous nucleation of calcite: molecular dynamics simulations of cluster formation and attachment

Melinda A. Fodor ${ }^{\mathrm{a}}$, Zoltán Ható ${ }^{\mathrm{b}}$, Tamás Kristóf ${ }^{\mathrm{b}}$, Mihály Pósfai ${ }^{{ }^{*}}$

${ }^{a}$ University of Pannonia, Department of Earth and Environmental Sciences, Veszprém, Hungary

${ }^{\mathrm{b}}$ University of Pannonia, Department of Physical Chemistry, Veszprém, Hungary

This Supplementary Information file contains 6 figures (Figs S1 to S6) and references to 3 movies (Movies S1 to S3) of molecular dynamics simulations, all of which are cited in the main text of the paper. These items are presented below in order of their callout in the paper. 

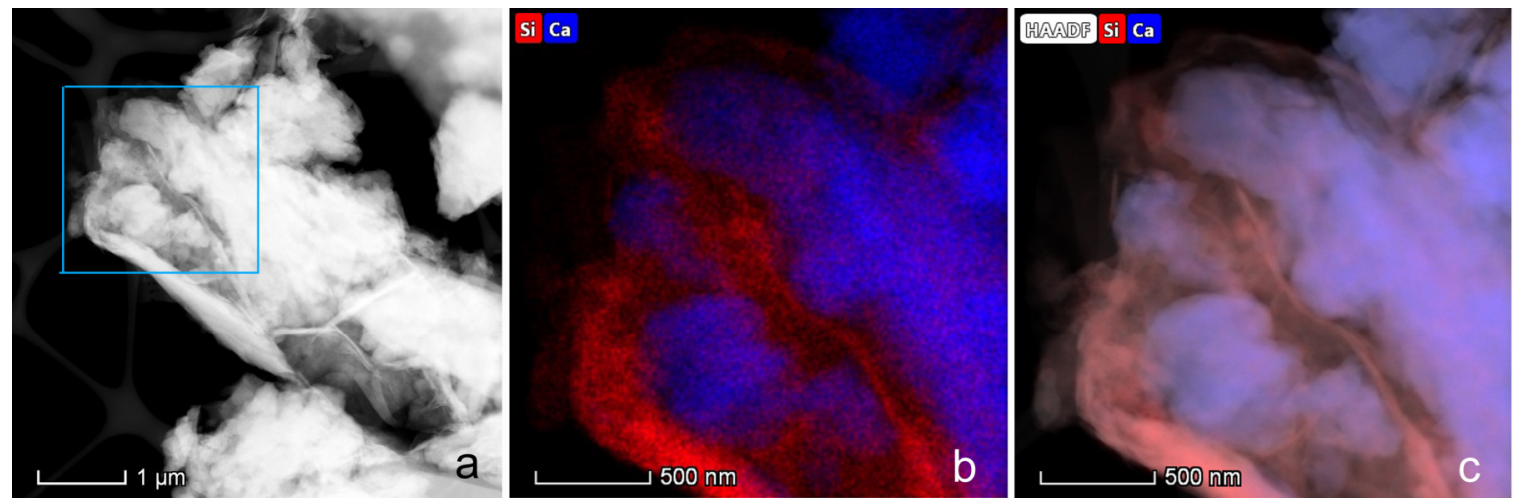

Figure S1. Association of smectite clays with Mg-bearing calcite crystals in suspended material from Lake Balaton, Hungary; (a) STEM HAADF image; (b) EDS map showing the distribution of $\mathrm{Ca}$ and $\mathrm{Si}$, and (c) a composite of a STEM image and EDS maps, obtained from the boxed area in (a).

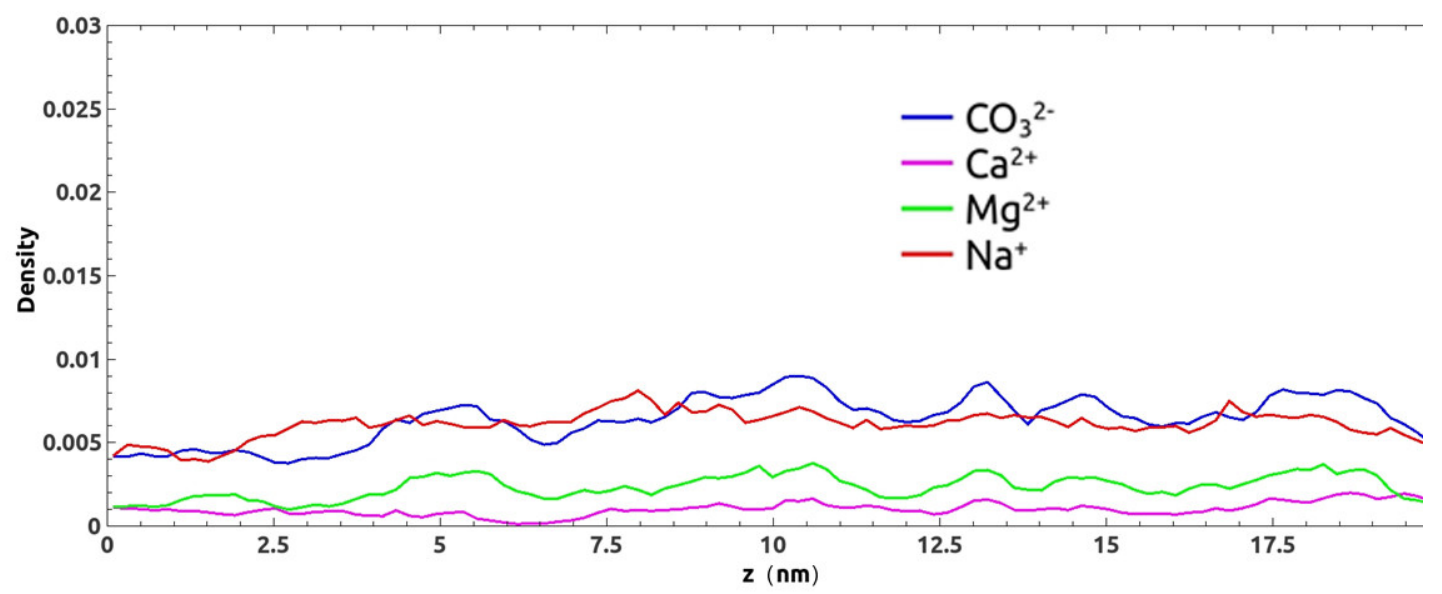

Figure S2. Density profile of the bulk-Na system, after $30 \mathrm{~ns}$ simulation, showing a uniform distribution of ions within the simulation box. 

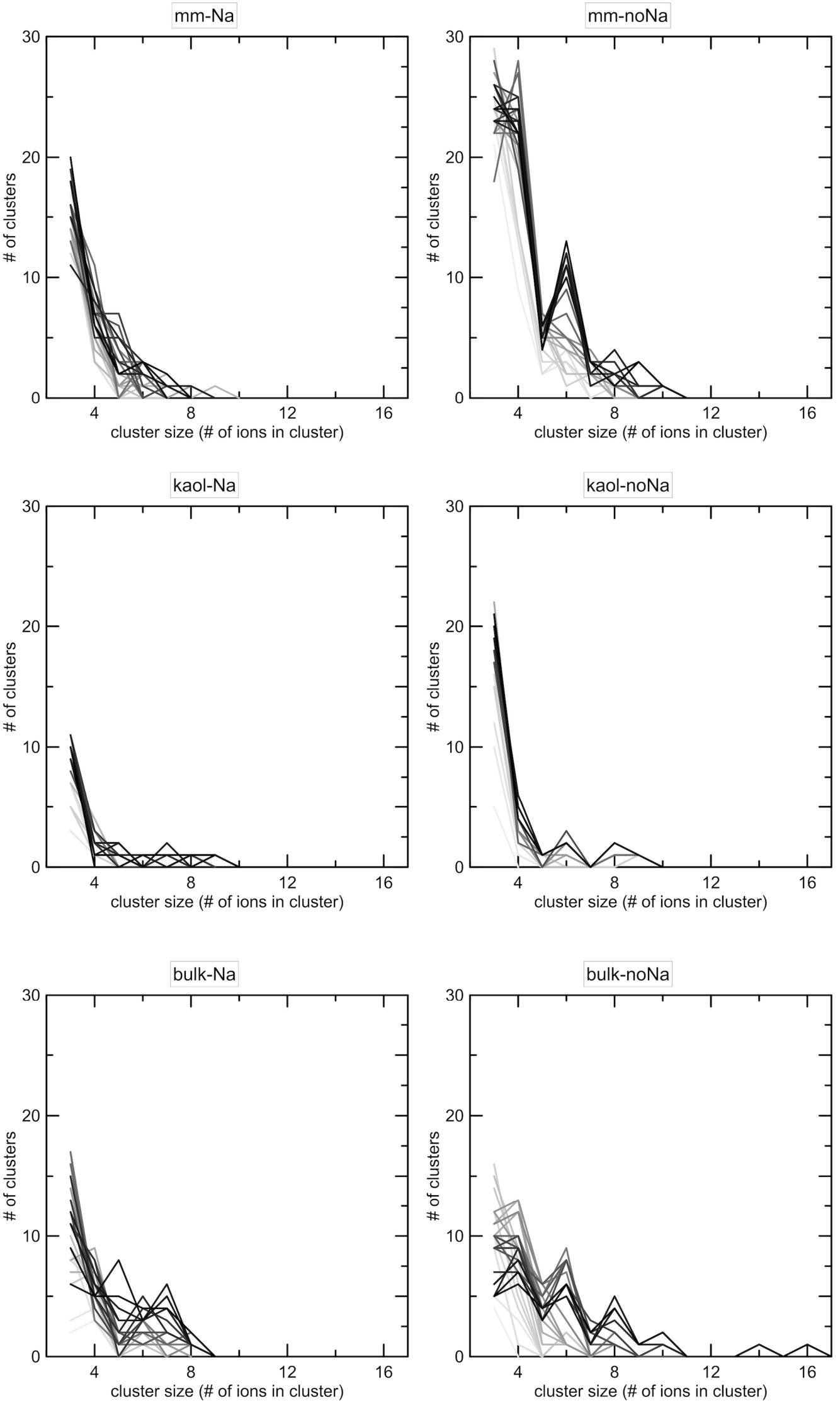

Figure S3. Evolution of cluster size distributions in six dilute systems over $30 \mathrm{~ns}$, shown at $1 \mathrm{~ns}$ time intervals (with the contrast of the curves increasing over time; thus, the darkest lines represent the cluster size distribution at $30 \mathrm{~ns}$ ). 


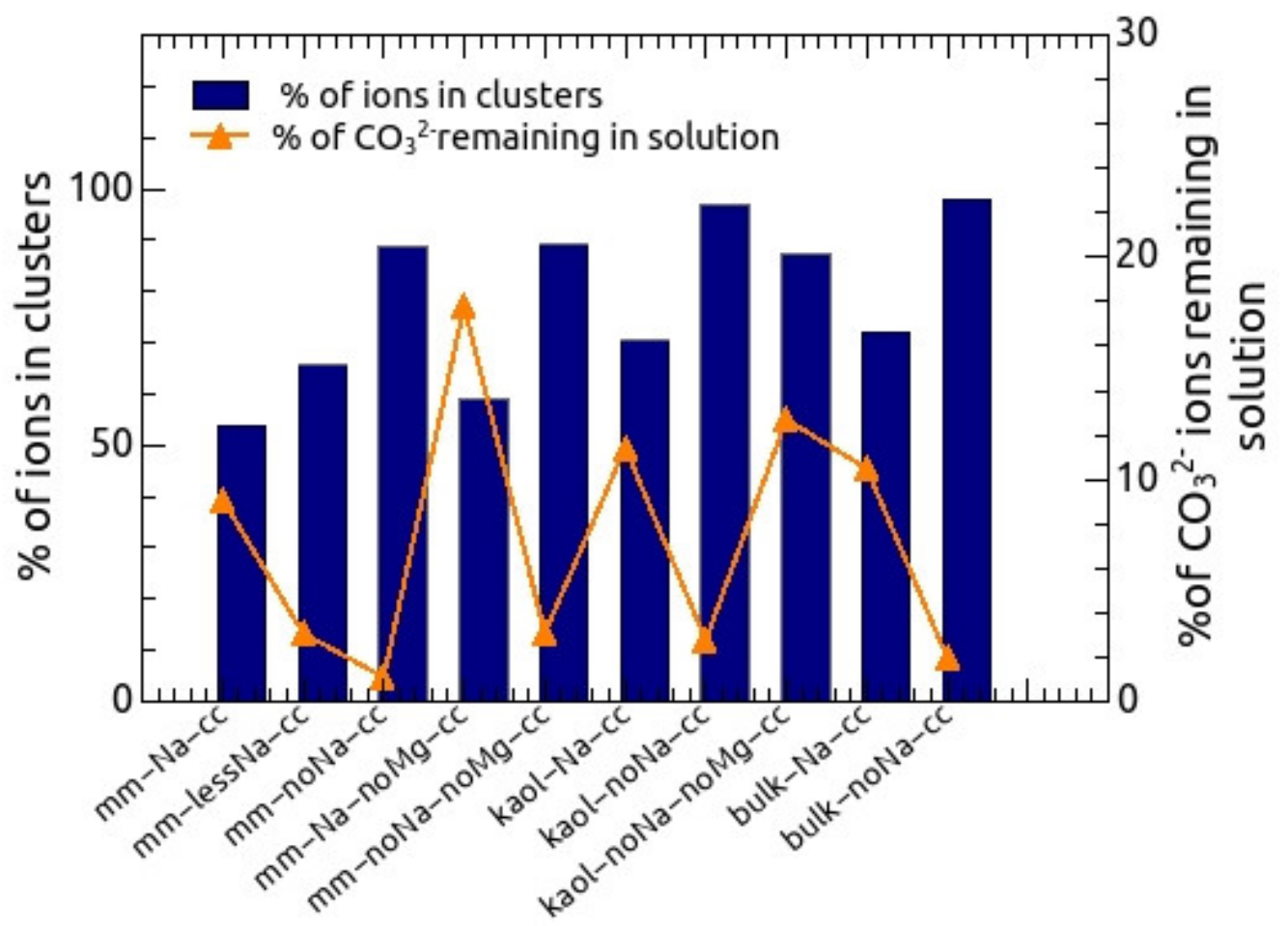

Figure S4. Cluster formation in the dense systems after $30 \mathrm{~ns} N V T$ simulation, with clusters defined as ion associations of 3 or more ions, showing the fraction of all ions that are included in clusters (left axis), and the number of remaining $\mathrm{CO}_{3}{ }^{2-}$ ions that are not involved in cluster formation (right axis) (this number involves free $\mathrm{CO}_{3}{ }^{2-}$ ions and those in ion pairs as well).

Movie S1. Cluster formation and movement in the 'mm-lessNa' system during the last $12 \mathrm{~ns}$ run of the 30 -ns simulation, shown in an orthogonal view. $\mathrm{CO}_{3}{ }^{2-}$ : red, $\mathrm{Mg}^{2+}$ : green, $\mathrm{Ca}^{2+}$ : pink, $\mathrm{Na}^{+}$: blue.

Movie S2. Cluster formation and movement in the 'mm-Na-cc' system during the last $12 \mathrm{~ns}$ run of the $30-\mathrm{ns}$ simulation, shown in a perspective view. $\mathrm{CO}_{3}{ }^{2-}$ : red, $\mathrm{Mg}^{2+}$ : green, $\mathrm{Ca}^{2+}$ : pink, $\mathrm{Na}^{+}$: blue. 

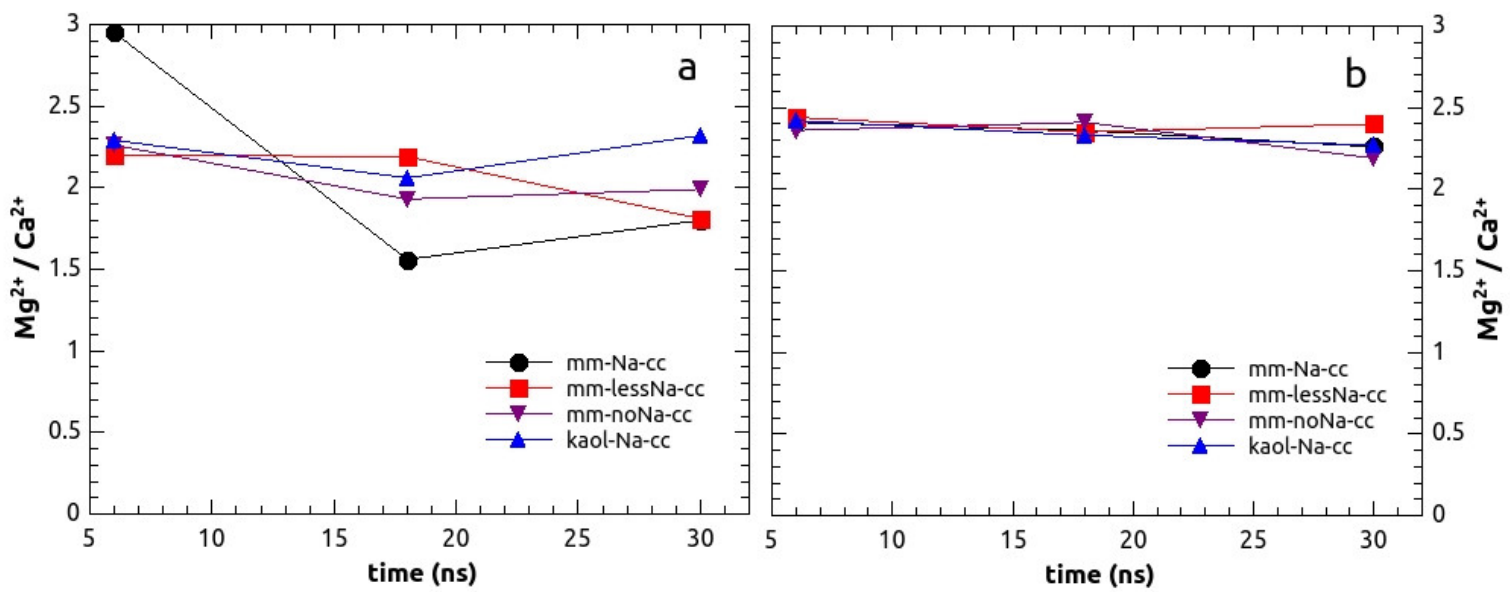

Figure S5. Evolution of the $\mathrm{Mg}^{2+} / \mathrm{Ca}^{2+}$ ratio of the clusters (a) near clay layers and (b) between the layers (interlayer space) in dense heterogeneous systems. 
Figure S6. Three snapshots from a short simulation run in the mm-Na system. The solvation states of several selected $\mathrm{Mg}^{2+}$ and $\mathrm{Ca}^{2+}$ ions (represented by green and magenta spheres, respectively) are shown at (a) 0; (b) 80 and (c) 120 ps runtime. Water molecules within the solvation shells of the selected cations at $0 \mathrm{ps}$ in (a) are indicated as small, v-shaped blue rods, and their movement is followed in (b) and (c). Water molecules newly captured from the solution are indicated as red $\mathrm{V}$-shaped rods in (b) and (c). An analysis of the blue and red water molecules suggests that within the very short (120 ps) runtime of this observation the hydrate shell around $\mathrm{Mg}^{2+}$ is stable, with hardly any of the water molecules exchanged. In contrast, most water molecules around $\mathrm{Ca}^{2+}$ are exchanged with those in the solution, while the number of water molecules in the solvation shell remains the same.
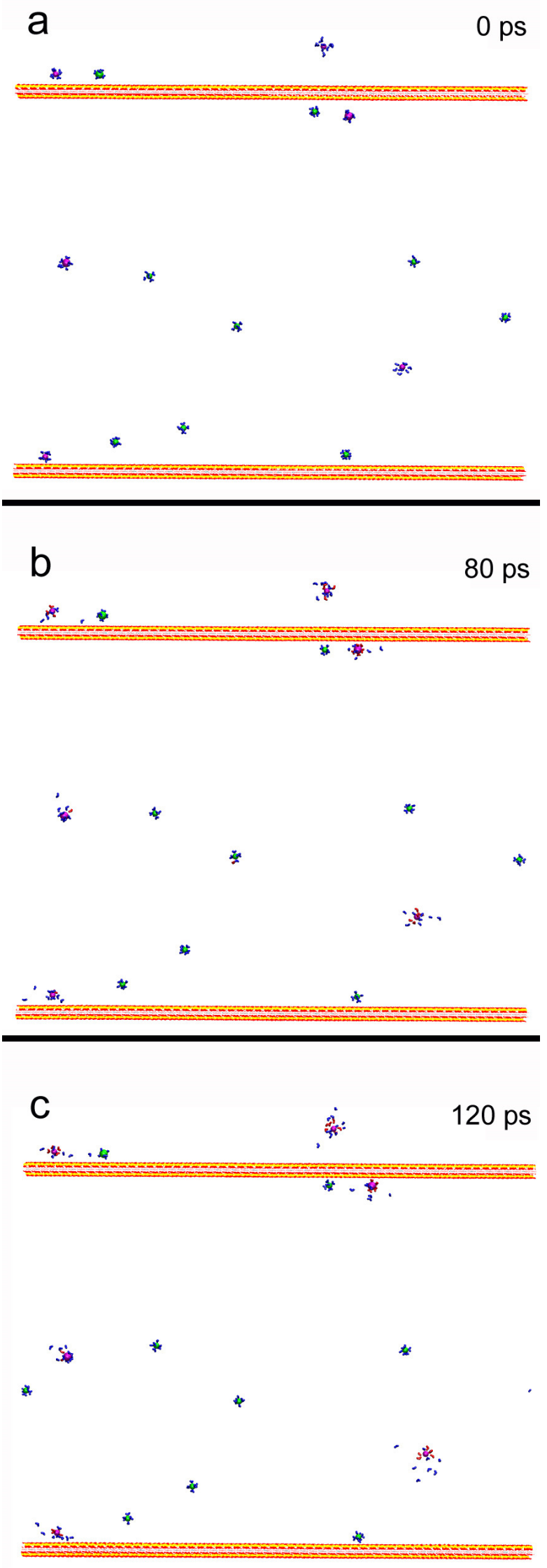
Movie S3. Cluster formation and movement in the ' $\mathrm{mm}$-noNa' system during the last 12 ns of the 30-ns simulation, with dynamic changes leading to cluster formation and disintegration. The hydration shells of the clusters are illustrated by the blue shaded area around the ions (water molecules within $0.4 \mathrm{~nm}$ of any ion are shown); the clusters attach to the clay surface through water molecules. $\mathrm{CO}_{3}{ }^{2-}$ : magenta, $\mathrm{Mg}^{2+}$ : blue, $\mathrm{Ca}^{2+}$ : yellow. 